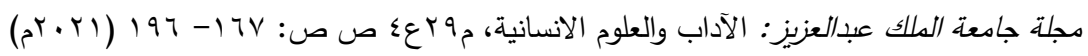

DOI:10.4197/Art.29-4.7

\title{
مداواة البكتيريا المقاومة للمضادات الحيوية (Clostridium difficile) بزراعة الفضلات البشرية (FMT)، دراسة طبية فقهية.
}

\author{
أ.د. أمل بنت محمد بن فالح الصغيّر \\ أستاذ الفقه في كلية الثربعة، جامعة الإمام محدد بن سعود الإسالاية \\ amsogir@imamu.edu.sa
}

\section{د. نجلاء بنت عبد الله بن سليمان بن عبيا

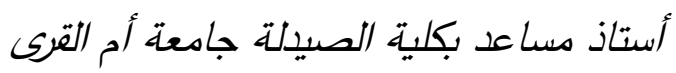 \\ naobaid@uqu.edu.sa}

مستخلص. فهذا ملخص لبحث: (مداواة البكتيريا المقاومة للمضادات الحيوية بزراعة فضلات الأمعاء البشرية،

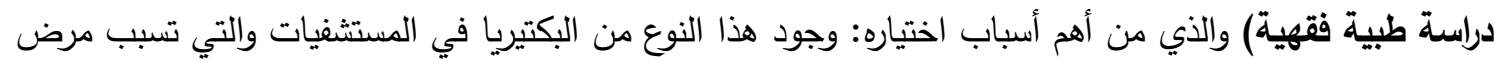
الإسهال المزمن للمرضى المنومين مما قد يؤدي إلى الوفاة و الحاجة لمعرفة الحكم الثرعي في مداواتها بزراعة الثرات الفضلات البشرية، فظهرت فكرة البحث من الناحية الطبية والفقهية، ويهدف إلى: معرفة طرق المداواة بهذه الطريقة وتكييفها الفقهي. وقد ثُسم البحث إلى تمهيد، ومبحثين، وخاتمة، فالتمعيد في حقيقة البكتيريا وطريقة حدوثها، وجاء في مطلبينهث

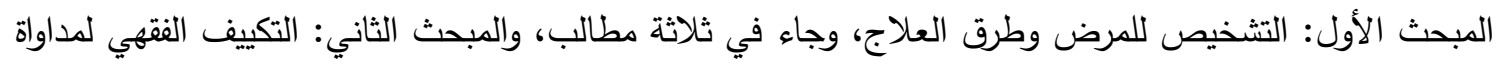
البكتيريا المقاومة للمضادات بزراعة الفضلات البشرية، وجاء في مطلبين.

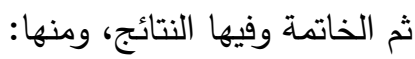

ا- أن لدداواة البكتيريا (Clostridium difficile) طريقتان: إما نوع من المضادات، أو زراعة الفضلات البشرية. ب- بلطريقة الزراعة أقسام ويختلف الدكم الثرعي باختلافها. ب- الأصل في مشروعية التداوي الإباحة. ع- الأصل في التداوي بالنجاسات التحريم.

ه- أن مداواة البكتيريا بزراعة الفضلات إن كانت عن طريق محلول الأنف أو كبسولات الفم فهي محرمة لوجود البديل الأخف منها ضررا. צ-أن مداواة البكتيريا بزراعة الفضلات عن طريق الحقن الثرجية أو منظار القولون فهي مباحة بضوابط إباحة

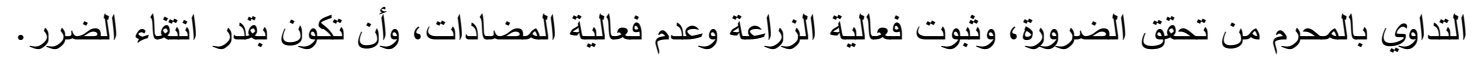

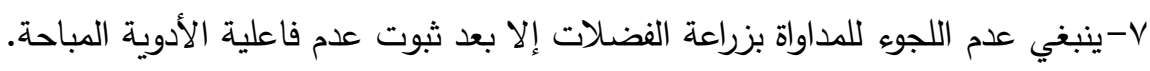


وأما التوصيات: فأوصت الباحثات بضرورة دراسة هذه النازلة طبيًا وفقهيًا على نطاق أكبر، ومحاولة إيجاد البديل

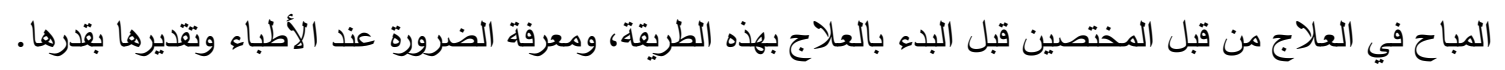

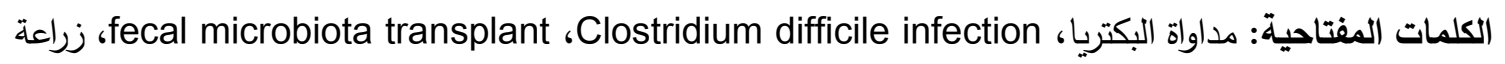

\section{أهمية الموضوع وأسباب اختياره:}

1- بداية ظهور هذا المرض لاى المرضى المنومين

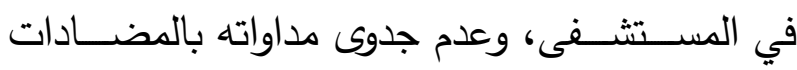

الحيوية كما أفادت الدراسات الطبية.

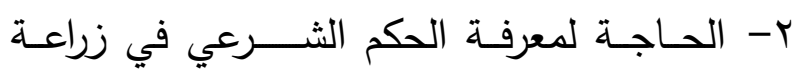

الفضلات البشرية واستعمالها للعلاج.

r- ضــرورة اجتماع الطبيب أو المختص الصـــي ولعي

والفقيه لدراسة النازلة الطبية الفقهية.

الههف من البحث:

معرفة طرق مداواة البكتريا المقاومة للمضــادات والتي متي قد تتســبب في موت الإنســان - بزراعة فضـــات مدات

الأمعاء البشريـة - وت وتأصيلها تأصيلاً شرعيًا.

الاراسات السابقة:

لم نجد - فيما اطلعنا عليه من مصادر - عند البحث من تتاول هذا الموضوع بالدراسة والبحث، وإنما غاية ما وُجد كتب وأبحاث عامـة في التداوي بالمحرمات

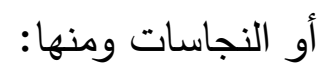

1- (التداوي بالمحرمات، دراســــة فقهية مقارنة)

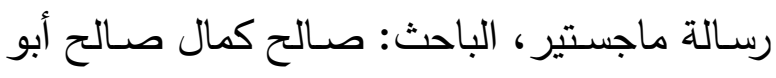
طه، الجامعة الإسلامية بغزة.

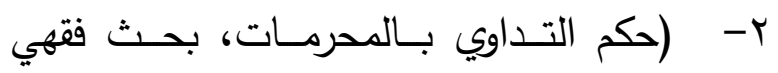
عقارن) كتاب منشــور د. عبد الفتاح إدريس، طا لـ

$$
\text { الفضلات البشرية، طب وفقه. }
$$

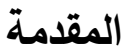

الحمد لله رب العالمين، والصـلاة والسـلام على نبينا محمد وعلى آله وصحبه ومن تبعهم بإحسان إلى يوم

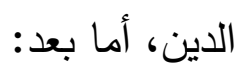

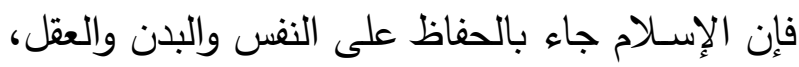

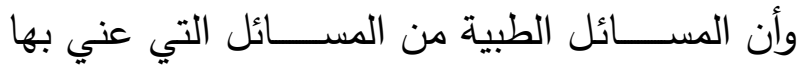
الفقهاء قديماً وحديثاً فتتاولوها بالبحث والدراسة؛ وذلك الكئ للعلاقة الوثيقة بين الفقه والطب في مجالات متعددة، فجميع المسـائل الطبية تخضــــ في الإنــلام لأحكام الثريعة، ومع تطور الطب فقد تظهر بعض القضـايا

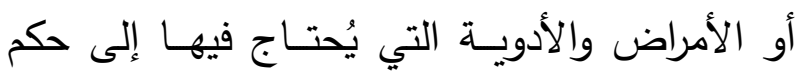

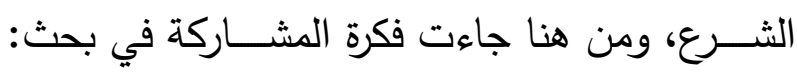

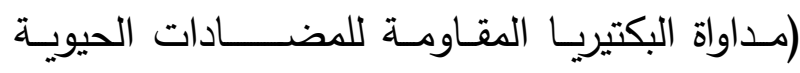
بزراعة الفضلات البشرية (Clostridium difficile) (FMT) ضابط الموضوع: يتــاول البحث: حكم التـاوي بفضــــــلات الآدميين

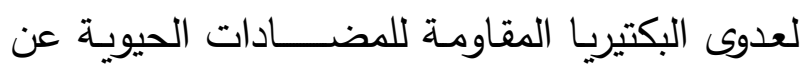
طريق تتـاولها ودخولها في بـدن الإنســــان بطرق

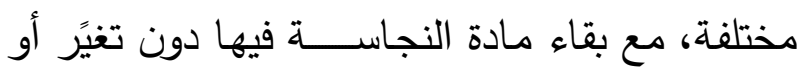
تحول. 
المطلب الثاني: طرق المداواة أو العلاج، وبدايـة

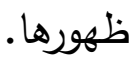

المطلب الثالث: طرق وأثـــكال زراعة مســـتخلص

$$
\text { فضلات الأمعاء البشرية. }
$$

المبحث الثاني: التكييف الفقهي لمداواة البكتريـا (Clostridium difficile) البشرية (FMT) وفيه مطلبان: المطلب الأول: حقيقة التداوي وحكمه، وفيه مسألتان:

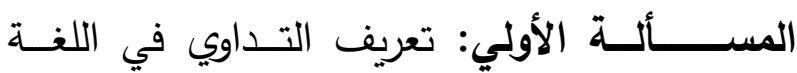
والاصطلاح. المسألة الثاني: حكم التداوي. المطلب الثـاني: حكم مـــاواة البكتريـا المقـاومــــ للمضـادات الحيوية بزراعة الفضـلات البشـرية: وفيه

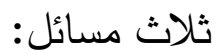
المسألة الأولى: تأصيل المسألة. المسألكة الثانية: حكم التداوي بنجس العين العين. المســـأنـة الثالثة: التكييف الفقهي لطرق المـاواة بزراعة فضلات الأمعاء البشرية.

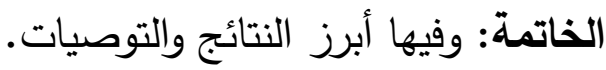
ملحق بصورة للأمعاء قبل وبعد العلاج.

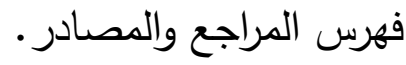

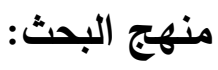
انقسم البحث إلى قسمين: القسم الطبي: وفيه اتبع الباحث المنهج الآتي: - البحث باستخدام الكلمات المفتاحية ( Clostridium (Fecal microbiota transplant) و في (difficile r- (أحكام التداوي بالمحرمات الحسـية في الفقه

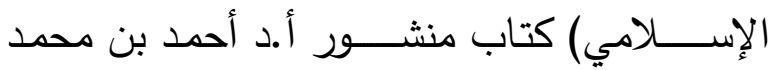
الخليل، طا، 0بـ اله، دار ابن الجوزي.

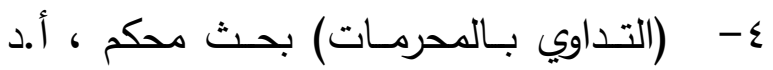
الوليد بن عبدالرحمن آل فرسان.

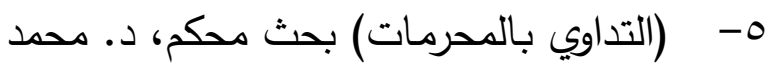

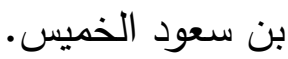
وهذه البحوث والرســــائل جميعها تتـاولت أحكام التداوي والمحرمات والنجاســـات عامة، ومنهم من خص الخمر أو أبوال الحيوانات في البحث، لكن هذا

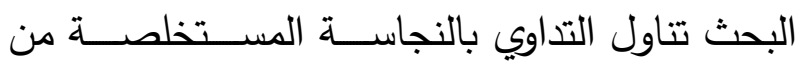
فضـــلات الأمعاء البشــرية كعلاج لمرض البكتيريا المقاومة للمضادات الحيوية.

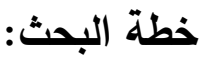

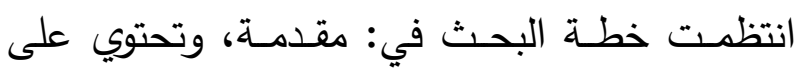

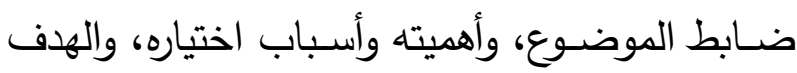
من البحث، والدراســات الســابقة، والخطة، والمنهج المتبع فيه. ثم التمهيد في: حقيقة البكتريا المقاومة للمضـــادات وطريقة حدوثها، وفيه: - تعريف البكتريا المقاومة للمضادات طبياً. - طريقة حدوثها. المبحث الأول: التثـــــيص للمرض، وعلاجه من الناحية الطبية: وفيه ثلاثة مطالب: المطلب الأول: التشخيص للمرض. 
- عزو الآيات لسورها من القرآن الكريم مع بيان رقم

- تخريج الأحاديث والأثار من مصادرها الأصلية. - عند التوثيق اقتصـر على ذكر المرجع، والمؤلف، مع الجزء والصــفحة مســبوقاً بكلمة (ينظر) إن كان النقل بتصرف، وبدونها إن لم يكن كذلك. هذا ونســـأل الله تعالى التوفيق والســـداد في القول والعمـل، وأن يتجـاوز عمـا حصــــل في البحث من جوانب التقصـــير والزلله، والحمد لله رب العـالمين وصلى الله وسلم على نبينا محمد وعلى آله وصحبه

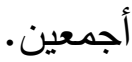

التمهيد: حقيقة البكتيريا المقاومة للمضادات

الحيويـة والمسماة

Clostridium difficile

أولاً: التعربف:

المثطية العسيرة (Clostridium difficile): هي

بكتيريا تتكاثر وتتمو في المرضى الذين يتعرضون للعلاج المكثف ولفترة طويلة بالمضادات الحيوية، مما يسبب لهم ضعف المناعة بسبب جلوسهح فترة طويلة كمرضى منومين داخل المستشفى ('). تتصنف هذه البكتيريا بأنها موجبة بصبغة القرام وهذا يعني بأن الخلية تحتوي على طبقة بيبتايدوجلايكان (كربوهيدرات وبيتايد) (ז)، وتحتوي البكتيريا الموجبة

Steele, J., N. Parry, and S. Tzipori, The roles of toxin (r) $\mathrm{A}$ and toxin B in Clostridium difficile infection: Insights from the gnotobiotic piglet model. Gut microbes, 2014. $.5(1)$ : p. $53-57$
المصــــادر وقواعد المعلومات الأجنبية وترجمتها و اعتمادا على خبرة الباحثة الطبية في مجال العدوى والكائنات الدقيقة الطبية وعلاجها بالأدوية. - تمت مراجعة الدراسـات والمقالات العلمية بالنسخة الالكترونية الصــــادرة عن دور نشـــر أجنبية وذكر المراجع المقتبس منها المعلومات وترجمتها. - تم التواصـل مع هيئة الغذاء والدواء الأمريكية عن طريق البريد الاكتروني وذلك لمعرفة آخر الإجراءات الطبية والقوانين المنظمة الصـادرة بخصـوص العلاج باســتخدام الفضـــلات البشــرية في علاج البكتيريا المقاومة للمضادات الحيوية. القسم الفقهي: هي: وفيه اتبع الباحث المنهج الآتي: - الاعتمـاد على المصـــــادر المعتبرة في الفقـه، مع الاطلاع والاستفادة من كتب المعاصرين والفتاوى. - أســلك في النازلة مســلك التخريـج إلى ما يشــابه المسألة مما ذكره الفقهاء. - تصوير المسألة إذا احتاجت إلى تصوير ، وضرب الأمثلة في ذلك. - تحرير محل الخلاف، وذكر الأقوال في المســألة إذا كانت محل خلاف مع الاقتصـــار على المذاهب الفقهية الأربعـة، وذكر الأدلة والمناقثــــات والترجيح وأسبابه.

Kelly, C. and J. Lamont, Antibiotic-associated (') diarrhea, pseudomembranous enterocolitis, and Clostridium difficile-associated diarrhea and colitis. Sleisenger and Fordtran's Gastrointestinal and Liver Disease, 9th edn. Saunders: Pennsylvania, 2010: p. 1889- 
المطلب الأول: التشخيص للمرض:

() يتم تشخيص المرض بأن يتعرف الطبيب على

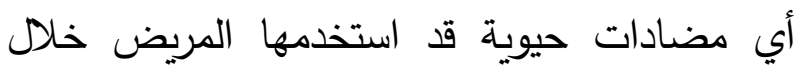
الست الثهور الماضية، تم التعرف على حدوث العدوى بسبب استخدام مثبطات مضخة البروتون (proton pump inhibitor) المعدة، والتشخيص المعملي يتم عن طريق فحص براز المريض. من الطرق المعروفة: () فحص وجود البكتيريا وزراعتها في المعمل باستخدام مزرعة بكتيرية مناسبة واستخدام صبغات خاصة مثل صبغة قرام السالفة الذكر وتحديد نوع البكتيريا بالفحص المجهري. وهذه الطريقة تحتاج الكثير من الوقت والجهد حيث إنها تتم خلال ع باعة من الحصول على العينة.

r) فحص وجود مادتين سامتين تفرزها البكتيريا وهي (سم A) و (سم B). وفحص الأجسام المضادة لاستكشاف المواد السمية والمستضد وهذا من ون الاختبارات المعملية التي تتم في مختبرات المستشفيات وتتم عن طريق فحص الأجسام المضادة في جسم المريض حيث ينتج جهاز المناعة الخاص بالإنسان أجسام مضادة لسموم هذه البكتيريا ( Clostridium

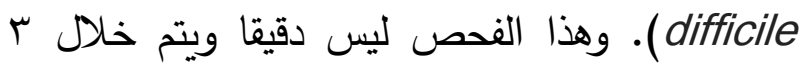

Rohlke, F., C.M. Surawicz, and N. Stollman, Fecal (r) flora reconstitution for recurrent Clostridium difficile infection: results and methodology. Journal of clinical .gastroenterology, 2010. 44(8): p. 567-570
القرام على طبقة سميكة تحبس الصبغة الزرقاء المستخدمة في صبغة القرام فتظهر باللون الأزرق بتدرجات مختلفة تحت المجهر عند فحصها، وتعتبر صبغة القرام من أدوات تشخيص البكتيريا للتمييز بين

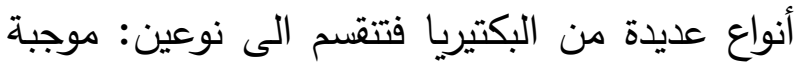

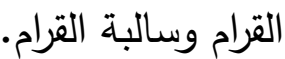

\section{ثانيًا: طريقة حدوث عدوى البكتيريا:}

يزدهر نمو هذه الفصيلة من البكتيريا في الأمعاء عندما يتم معالجة المريض بالمضادات الحيوية لمدة طويلة مما يؤدي إلى التهاب القولون الغشائي الكاذب (') (Pseudomembranous colitis) هذه البكتيريا أحد أنواع البكتيريا المتواجدة بشكل

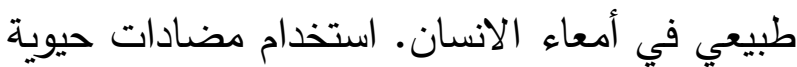
واسعة المجال مثل: (سيفالوسبورين، الأموكسسيسلن) و أدوية بيتا لاكتام يؤدي الى نقص شديد في مجموع البكتيريا النافعة المعوية في القولون فيكون لدى البكتيريا المتبقية مجال أوسع للنمو لتوفر المكان المناسب والغذاء والبكتيريا المتبقية مثل البكتيريا المثطية العسيرة (Clostridium difficile) تبقى وتتمو وتفرز مواد سامة تؤدي إلى التهاب القولون

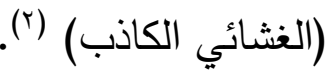

المبحث الأول: التثــــيص للمرض، وعلاجها من الناحية الطبية: وفيه ثلاثة مطالب:

Kelly, C. and J. Lamont, Antibiotic-associated ( ') diarrhea, pseudomembranous enterocolitis, and Clostridium difficile-associated diarrhea and colitis. Sleisenger and Fordtran's Gastrointestinal and Liver Disease, 9th edn. Saunders: Pennsylvania, 2010: p. 1889- 
طريق الفم أربع مرات باليوم لمدة عشرة أيام و في حالة

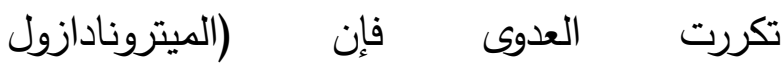

يستخدم بالإضافة إلى (Metronidazole)

(الفانكوميسن (ثلاث مرات باليوم لمدة عشرة أيام (') بعض الحالات يحصل عدم فعالية هذا العلاج حيث تم تسجيل انعدام فعالية العلاج (بالفانكوميسين والميترونادازول) في 0 1-، ٪ من الحالات (1). وحصول مقاومة (للفانكوميسن) عند هؤلاء المرضى بسبب وجود عدوى البكتيريا من سلالة أشد ضررًا. وقد يحصل عدة انتكاسات للمرضى حتى بعد معالجتهم (بالفانكوميسين) فلذلك يجدر على الطبيب إدخال أسلوب علاجي آخر للتغلب على هذه العدوى أحد اختيارات العلاج أيضا يتضمن استخدام مضاد (الريفاميكسين (Rifaximin) عن طريق الفم أو (ب) • (') (Fidaxomicin) (فيداكسومسين)
ساعات للحصول على النتيجة، لذا تم اتباع طرق

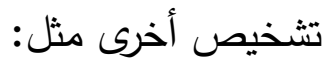
r) إجراء اختبار اكتشاف وتفاعل البوليمرات المتسلسلة لجينات البكتيريا، حيث يتم أخذ عينة بسيطة مثل مسحة وعمل استكثار جينات البكتيريا ووضع مواد كاشفة خاصة بالخلايا البكتيرية ويتم إعطاء نتيجة بطريقة آلية باستخدام أجهزة متطورة ويتم إعطاء النتيجة خلال 0ـ دقيقة فقط.

\section{المطلب الثاني: طرق العلاج وبداية ظهورها:} أولاً: العلاج بالمضادات الحيوية:

لعلاج هذه العدوى ولمعالجة التهاب غشاء القولون الكاذب يعتمد على مستوى هذه العدوى وخطورتها وتكرر العدوى، والعلاج المتعارف عليه غالبًا هو استخدام مضاد (فانكوميسين (Vancomycin) عن

وفي الجدول الآتي العلاج الموصى به لهذه العدوى مختصرًا:

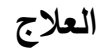

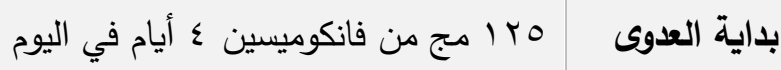

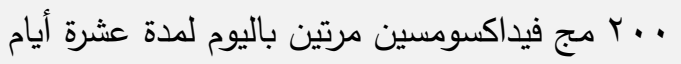

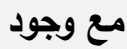

اعراض خفيفة/ أو .0 مج ميترونيدازول ثلاث مرات باليوم لمدة عشرة أيام إذا لم يكن الفانكومايسين والفيداكسومسين مئن

$$
\text { متوفرا او لوجود حساسية }
$$

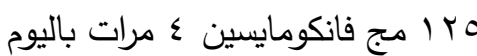

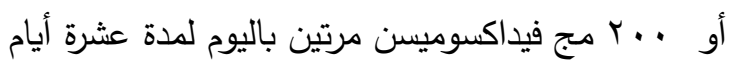

متوسطة

باية العدوى

مع أعراض بله

شديدة - مائ
McDonald, L.C., et al., Clinical practice guidelines ( $\left.{ }^{(}\right)$ for Clostridium difficile infection in adults and children: 2017 update by the Infectious Diseases Society of America (IDSA) and Society for Healthcare Epidemiology of America (SHEA). Clinical Infectious .Diseases, 2018. 66(7): p. e1-e48
McDonald, L.C., et al., Clinical practice guidelines (') for Clostridium difficile infection in adults and children: 2017 update by the Infectious Diseases Society of America (IDSA) and Society for Healthcare Epidemiology of America (SHEA). Clinical Infectious .Diseases, 2018. 66(7): p. e1-e48 


\begin{tabular}{|c|c|}
\hline الأوبلى مج فانكوميسين أربع مرات باليوم لمدة عشرة أيام إذا كان ميتروندازول قد تم استخدامه في العدوى & للدمر الثانية متكرة \\
\hline 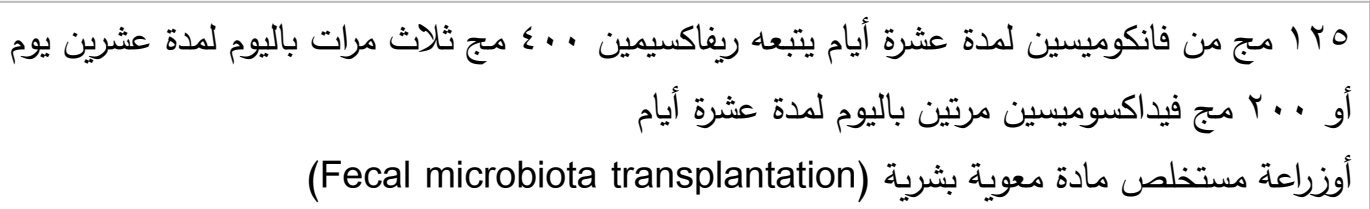 & لأكثر من من متكرة \\
\hline
\end{tabular}

"FMT" Fecal microbiota ) البكتيريا النافعة (transplant وهي بأن تعيد بناء بيئة البكتيريا النافعة في أمعاء المصاب بالتهاب الغشاء المعوي والتي حدثت عن طريق عدوى بكتيريا (C. difficile). وجدت الدراسات بأن هذه الطريقة تساعد على إعادة بناء جدار الأمعاء للشخص المصاب بتغيير بيئة الأمعاء من جديد لبيئة صحية فيها تجمع من الألياف والأنزيمات المهمة ومجموعة البكتيريا النافعة. بدأ المهتمين بهذه النظرية دراسة الحالات التي تم علاجها بالطريقة (FMT) ومنها دراسة في عام r... r م على 11 حالة تم علاجها بمستخلص الأمعاء البشرية (FMT) وسجلت حالات شفاء بنسبة

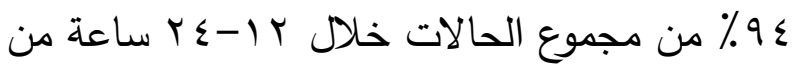
العلاج بمجموع البكتيريا النافعة المأخوذة من الأمعاء

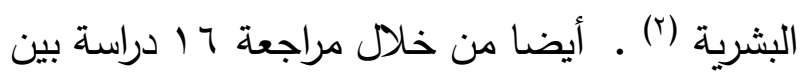
الأعوام 1901 وحتى ^ . . 1 م تضمنت 109 حالة مرضية لمرضى لديهم عدوى أدت الى التهاب امعاء patients treated with donor stool administered via a nasogastric tube. Clinical infectious diseases, 2003. $.36(5)$ : p. $580-585$
ثانيًا: العلاج بطريقة زراعة مستخلص مادة معوية بثريـة (Fecal microbiota transplant) لتعزيز الأمعاء بالبكتيريا النافعة: استخدمت هذه الطريقة من العلاج لأول مرة عندما عالج الدكتور ايسمان (Eiseman) حقنة عن طريق فتحة الشرج تحتوي على مستخلص المادة المعوية من إنسان سليم وذلك لعلاج مصاب بالتهاب الأمعاء الغشائي الكاذب عام 901 19 ('). إن استخدام المضادات الحيوية بشكل مكثف يعمل على تغيير في بيئة الأمعاء الداخلية التي تحتوي على التى عدة أنواع من البكتيريا النافعة، وتعمل هذه البكتيريا النافعة كخط دفاع أول لذلك برزت فكرة العلاج بالمادة المتكونة من هذه البيئة المعوية والتي تحتوي على عدة مكونات وهي الألياف الغذائية المتبقية من عملية الهضم وإنزيمات الأمعاء ومجموعة أنواع من البكتيريا النافعة. النظرية المنبثقة من هذا التدخل العلاجي بزراعة مستخلص مادة معويـة بشرية تحتوي على

Eiseman, B., et al., Fecal enema as an adjunct in the (') treatment of pseudomembranous enterocolitis. Surgery, 1958. 44(5): p. 854-9 Aas, J., C.E. Gessert, and J.S. Bakken, Recurrent ( () Clostridium difficile colitis: case series involving 18 
فشل العلاج بالمضادات الحيوية ( الصف الأول من علاج هذه العدوى) عن طريق بالعيقات العلاج بزراعة مستخلص الأمعاء البشرية المستخرجة من أمعاء شخص سليم (זّ). هذا العلاج يتضمن زراعة مادة مستخلصة من أمعاء شخص طبيعي غير مريض حيث ان المادة المستخلصة تحتوي على كمية البكتيريا النافعة الطبيعية. تتم عن طريق عملية زراعة محلول ملحي طبي يتكون من مادة مستخلصة من فضلات

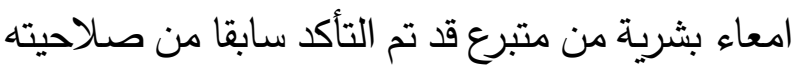

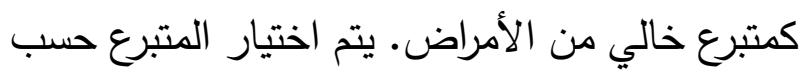
عدة معايير وهي ان يكون مثلا: عمره ما بين 17 و •T سنة، وزن متناسب ولايعاني من السمنة و

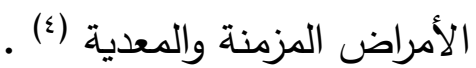
المطلب الثاني: طرق وأثكال زراعة مستخلص المرانه فضلات الأمعاء البشرية: تتم زراعة المحلول عن طريق أنبوب معوي أو قسطرة شرجية لضمان دخول هذا المحلول إلى الجزء الملتهب في القولون (०). . ريتم تحضير المستخلص بعدة طرق، هذه الطرق يتم تحديدها حسب إمكانات المستشفى أو لون

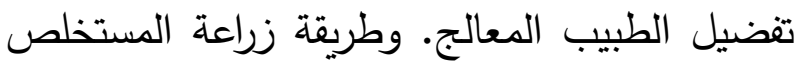

America (IDSA) and Society for Healthcare Epidemiology of America (SHEA). Clinical Infectious .Diseases, 2018. 66(7): p. e1-e48 Goldenberg, S.D., et al., Comparison of different (\&) strategies for providing fecal microbiota transplantation to treat patients with recurrent Clostridium difficile infection in two english hospitals: a review. Infectious .diseases and therapy, 2018. 7(1): p. 71-86 Tauxe, W.M., et al., Fecal microbiota transplant ( ${ }^{\circ}$ protocol for clostridium difficile infection. Lab Med, .2015. 46(1): p. e19-23
تم علاجهم بطريقة FMT وتم شفاء 19 \% من الحالات

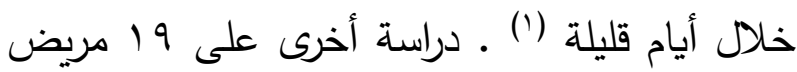

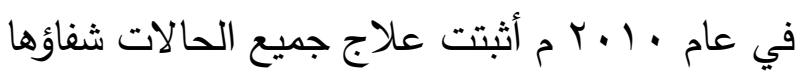

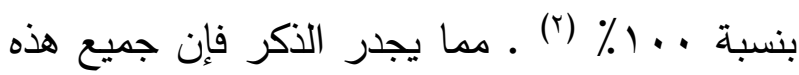

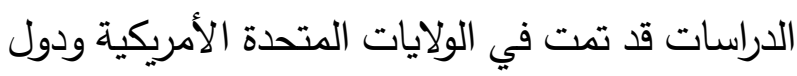
أوروبية. أيضا لم يتم ذكر أي من التأثيرات الجانبية

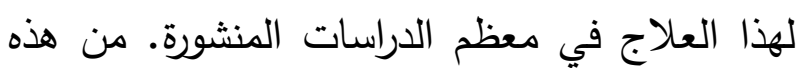
الدراسات ذكرت بعض الأعراض الجانبية البسيطة مثل الغثيان وغازات البطن فقط ولم يتم ذكر اعراض جانبية أخطر من ذلك. كل هذه التجارب والدراسات الغربية لا نستطيع الجزم بشكل مطلق بأن العلاج بهذه

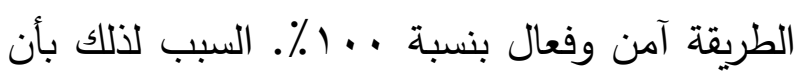
جميع هذه الدراسات تضمنت عدد قليل من المرضى وليست بشكل عشوائي مما يجعلها ليست متوافقة . . . . مع أسلوب التحقيق بالأدلة العلمية وتحتاج لعدة دراسات مستقيضة للبت بها كعلاج للمرضى. وحديثا أصدرت جمعية الأمراض المعدية الأمريكية وجمعية الرعاية الصحية للوبائيات الأمريكية (IDSA) (SHEA ) المتكرر بسبب هذه البكتيريا (C. difficile) والذي لوني

Van Nood, E., et al., Struggling with recurrent (1) Clostridium difficile infections: is donor faeces the .solution? Eurosurveillance, 2009. 14(34): p. 19316 Yoon, S.S. and L.J. Brandt, Treatment of ( r) refractory/recurrent C. difficile-associated disease by donated stool transplanted via colonoscopy: a case series of 12 patients. Journal of clinical gastroenterology, 2010.

$.44(8):$ p. $562-566$

McDonald, L.C., et al., Clinical practice guidelines (") for Clostridium difficile infection in adults and children: 2017 update by the Infectious Diseases Society of 
ويمكن الاحتفاظ بالمادة المستخلصة من الأمعاء

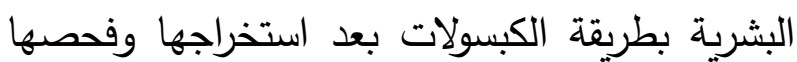
من المتبرع وتحضيرها وحفظها في درجة حرارة سالب

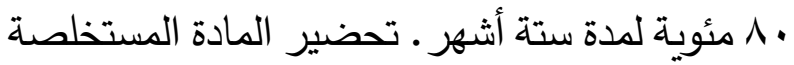

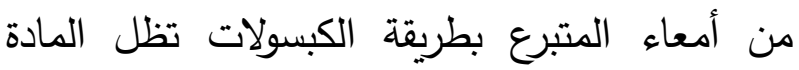
محتفظة بأصلها ولا تتغير خاصيتها. تستخدم هذه الأشكال وتقدم للمريض حسب إنبا هـانيات

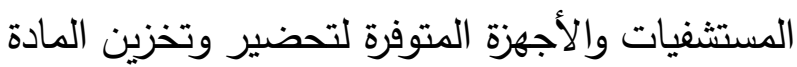
من المتبرعين. ويوجد عدة طرق لإعطاء المريض الاشكال المحضرة من المادة المستخلصة من أمعاء

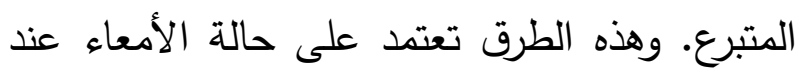

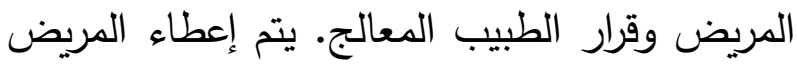
الأشكال المحضرة حسب الطرق التالية:

1. إدخال المحلول السائل المحضر بالطريقة المذكورة سابقا بثلاثة طرق: أنبوب محاليل بمنظار

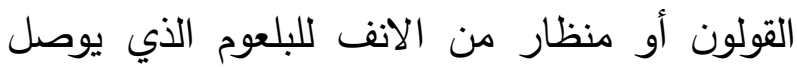
المحلول للأمعاء المصابة بالعدوى أوعن طريق الحقنة الشرجية مباشرة للأمعاء. r. باستخدام الكبسولة المحضرة من المتبرعين والتي تم تخزينها في درجة حرارة منخفضة يتم إعطاء المريض عن طريق الفم. وهذه الطريقة تستخدم عند

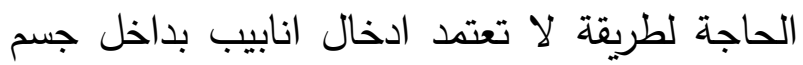
المريض.

Youngster, I., et al., Oral, frozen fecal microbiota (r) transplant (FMT) capsules for recurrent Clostridium .difficile infection. BMC medicine, 2016. 14(1): p. 134
أيضا تعتمد على شكل المادة المستخدمة والتي تم تحضيرها من مستخلص الأمعاء.

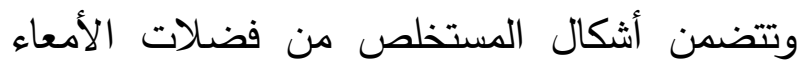
البشرية ما يأتي:

ا. محلول ملحي مضاف إليه المادة المستخلصة لئه المراد زراعتها. يتم تحضير المستخلص بعد الحصول

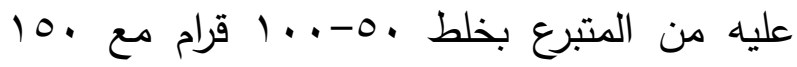

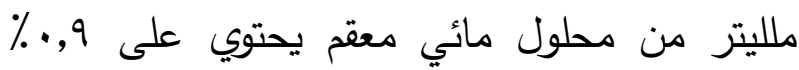

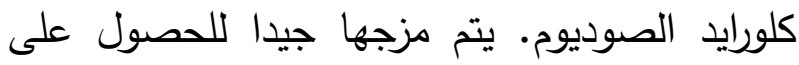
محلول سائل يخلط بعد ذلك بجلسرين (1, r 1\%) (') . هذا التخفيف يتم باحتفاظ المستخلص لأصل المادة

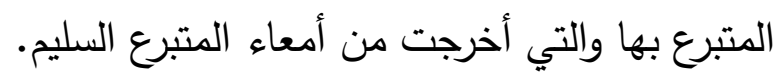
r. كبسوله محضرة من المادة المستخلصة المراد زرعها. يتم تحضير الكبسولة عن طريق تخفيف المادة المستخلصة كما هو موضح سابقا مع محلول مائي

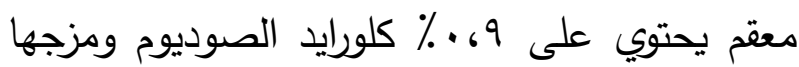
جيدا ثم استخدام المنخل لنخلها وبعد ذلك تركيزها باستخدام جهاز الطرد المركزي الذي يجعل المادة مضغوطة وملتصقة ببعضها وتحجيمها لحجم صغير لهري ومركز كالكبسولة. بعد ذلك المادة المضغوطة يضاف اليها مادة تستخدم في تغليف الكبسولات متكونة من سيليلوز مثل مادة هايبرميلوز (hypromellose) ثم في ماده تحفظ في درجة حرارة سالب.^ درجة مئوية (؟)،

Goldenberg, S.D., et al., Comparison of different (') strategies for providing fecal microbiota transplantation to treat patients with recurrent Clostridium difficile infection in two english hospitals: a review. Infectious .diseases and therapy, 2018. 7(1): p. 71-86 
التي تكونت كمقاومة للمضادات الحيوية (r) البكتيريا تكونت بكمية مرضية ثم تحورت C. difficile وأصبحت مقاومة للمضاد خلال مدة علاج العدوى الطويلة بالمضادات الحيوية (r) العلاج بزراعة البيئة البكتيرية النافعة بداخل أمعاء المصاب عن طريق (FMT) قد أظهرت نسبة شفاء لأعراض الغشاء المعوي الكاذب وللعدوى البكتيرية بسبة 19\% حتى الآن (£). وأسلوب التدخل العلاجي هذا يجب أن يكون تحت عدة اشتراطات قد حددتها هيئة الغذاء والدواء الأمريكية (FDA) في نشرتها المتضمنة عدد من التوصيات الخاصة بعلاج هذه العدوى البكتيرية المستعصية (0). من هذه الاشتراطات التي تكون تحت مسمى بند متطلبات استقصاء طريقة علاج جديدة (IND)، حيث تستقصي الهيئة عدة معطيات لهذا الأسلوب العلاجي المستحدث بالنظر إلى مخرجات من الأبحاث الاستقصائية للطريقة

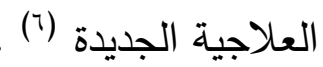

Aas, Johannes, Charles E Gessert, and Johan S Bakken. "Recurrent Clostridium Difficile Colitis: Case Series Involving 18 Patients Treated with Donor Stool Administered Via a Nasogastric Tube." Clinical infectious diseases 36, no. 5 (2003): 580-85.36(5): p. 580-585.

Dethlefsen, L., et al., The pervasive effects of an antibiotic on the human gut microbiota, as revealed by deep $16 \mathrm{~S}$ rRNA

.(sequencing. PLoS biology, 2008. 6(11

Van Nood, E., et al., Struggling with recurrent Clostridium (₹) difficile infections: is donor faeces the solution? .Eurosurveillance, 2009. 14(34): p. 19316 Food, U. and D. Administration, guidance for industry: Enforcement policy regarding investigational new drug requirements for use of fecal microbiota for transplantation to treat Clostridium difficile infection not responsive to .standard therapies. 2016. 2019

Food, U. and D. Administration, guidance for industry: Enforcement policy regarding investigational new drug requirements for use of fecal microbiota for transplantation
جميع هذه الأساليب تم استخدامها في الدراسات المقارنة لمعرفة مدى سلامتها ومدى فعاليتها في طريقة العلاج FMT. وهذه الدراسات مستمرة في قياس فعالية الطرق والاشكال العلاجية.

عند زراعة المستخلص FMT المحتوي على كمية بكتيريا نافعة من أمعاء المتبرع فهي تعمل بطريقة فعالة في إعادة نمو هذه البكتيريا النافعة في أمعاء المصاب وتعيد تكوين بيئة التي يعتقد بأنها ستوقف عمل البكتيريا (Clostridium difficile) المسببة للعدوى وذلك بآليات معينة ('). عندما يفشل العلاج بالمضادات الحيوية والتي تكون غالبا علاج خلال مدة طويلة وأدى ذلك الى تكرر العدوى عدة مرات فإن ميزة العلاج بزراعة بيئة بكتيرية نافعة (FMT) تتضح عندما نوقف استخدام المضادات الحيوية كعلاج. فإننا عندما نوقف العلاج بالمضادات الحيوية ونستبدلها بطريقة أخرى تمكننا من إعادة احياء البكتيريا النافعة في الأمعاء وهي بدورها لتثبيط نمو البكتيريا المضرة

McDonald, L.C., et al., Clinical practice guidelines (') for Clostridium difficile infection in adults and children: 2017 update by the Infectious Diseases Society of America (IDSA) and Society for Healthcare Epidemiology of America (SHEA). Clinical Infectious

.Diseases, 2018. 66(7): p. e1-e48 Aas, Johannes, Charles E Gessert, and Johan S Bakken. ( "Recurrent Clostridium Difficile Colitis: Case Series Involving 18 Patients Treated with Donor Stool Administered Via a Nasogastric Tube." Clinical infectious diseases 36, no. 5 (2003): 580-85.36(5): p. 580-585 Dethlefsen, L., et al., The pervasive effects of an antibiotic on the human gut microbiota, as revealed by deep 16S rRNA Dethlefsen, L. and .(sequencing. PLoS biology, 2008. 6(11 D.A. Relman, Incomplete recovery and individualized responses of the human distal gut microbiota to repeated antibiotic perturbation. Proceedings of the National Academy of Sciences, 2011. 108(Supplement 1): p. 4554- 
بشكل أوسع لتفادي مثل هذا التأثير الجانبي والموازنة

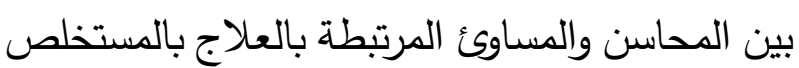
المعوي (FTM).

المبحث الثاني: التكييف الفقهي لمـاواة البكتريـا المقــاومسة للمضـــــادات (C. difficile) بزراعــة الفضلات البشرية (FMT) وفيه: المطلب الأول: حقيقـة التــاوي وحكمـه، وفيـهـ مسألتان:

المســــأـــة الأولى: تعريف التــاوي في اللغــة والاصطلاح: التداوي في اللغة:

مصـدر تداوي: أي تتاول الدواء (r)، وداواه: عالجه، يُقِال: فلان يُدوْي ويُدَاوي، وتداوى بالثيء : تعالج باه.

والداء: اســــ جامع لكل مرض وعيب في الرجال ظاهر أو باطن حتى يقال: داء الثــح أثــــ الأدواء.

\section{التداوي في الاصطلاح:}

عُرف التداوي في الاصطلاح بأنه: استعمال ما يكون الاصطواح به شــفاء المرض بإذن الله تعالى من عقار أو رقية

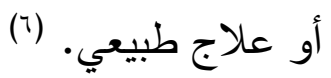

Review and Meta-Analysis. Gastroenterology, 2019. .156(6): p. S-906-S-907

DeFilipp, Z., et al., Drug-Resistant E. coli Bacteremia ( Transmitted by Fecal Microbiota Transplant. N Engl J .Med, 2019. 381(21): p. 2043-2050

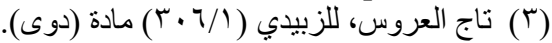

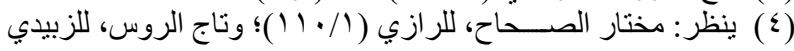

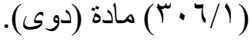

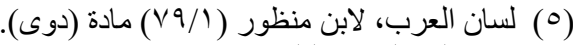

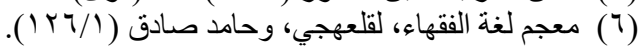

تم استحداث طرق مختلفة لاستخدام هذا الأسلوب العلاجي أنه قد يعطى للمريض بعدة أشكال دوائية وقد

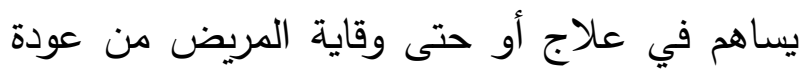

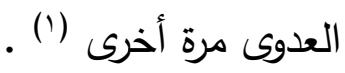

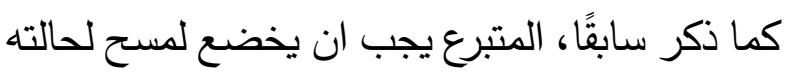
الصحية وخلوه من الامراض الهضمية والمعدية

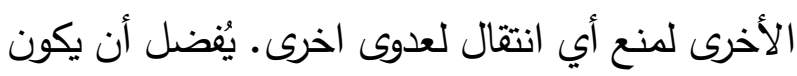
المتبرع من الأشخاص المخالطين للمريض وذلك لأن لأن المخالطين يتشاركون بيئة بكتيرية معوية متشابهة

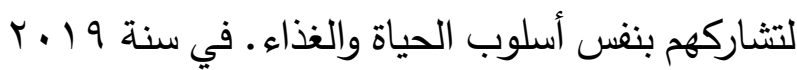
م تم نشر دراسة وصفت حدوث تأثير جانبي خطير

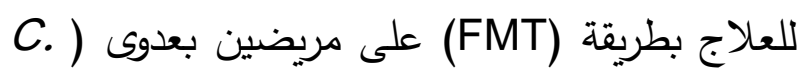

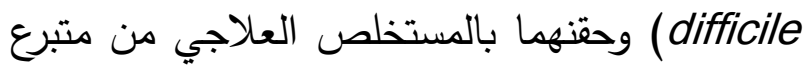
بالمكونات المعوية الخاصة به التي اكتشف لاحقا بأن

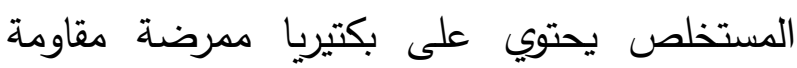

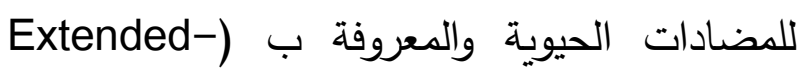
spectrum beta-lactamase (ESBL) ( producing Escherichia coli المرضى توفي بسبب هذه العدوى الأخيرة وتم التعرف على مصدر العدوى من نفس المتبرع. وخرجت التوصية في هذه الدراسة بعمل مسح شامل للمتبرعين

to treat Clostridium difficile infection not responsive to .standard therapies. 2016. 2019 Reigadas, E., et al., Fecal microbiota transplantation for (') recurrent Clostridium difficile infection: Experience, protocol, and results. Revista Española de Quimioterapia, .2018. 31(5): p. 411

Ramai, D., et al., Mo1970-Efficacy of Colonoscopy, Nasogastric Tube, Enema, and Capsule Fecal Microbiota Transplantation in the Treatment of 1,191 Patients with Recurrent Clostridium Difficile Infection: A Systematic 
وقيل هو: تتـاول المريض الدواء أو قيـامـهـ بإجراء وجه الدلالة:

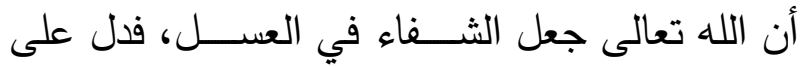
جواز التعالج بشــربه إدراكاً للثـــفاء خلافاً لمن كره

ذلك. ()

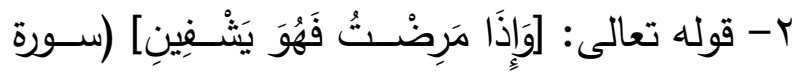

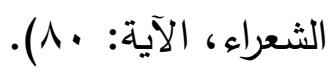

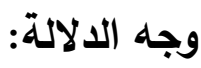

أن الآية دلت على أن الثـــــاء من الله تعالى، وقد

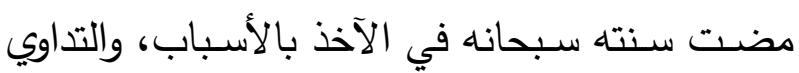

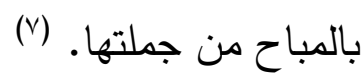

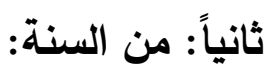

1 - حديث أبي هريرة - رضـي الله عنه - أن النبي

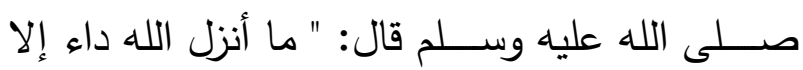

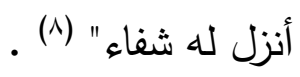
r- حديث أسامة بن شريك - رضي الله عنه - أن

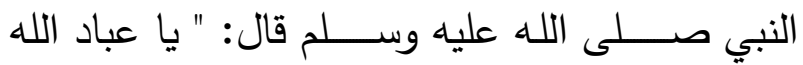

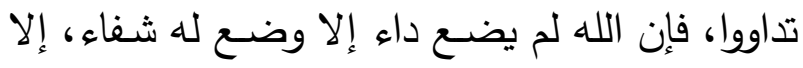

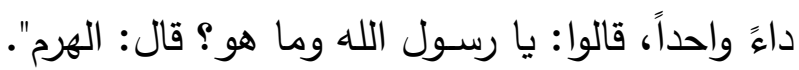

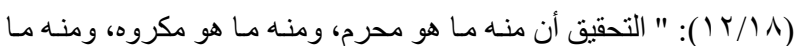

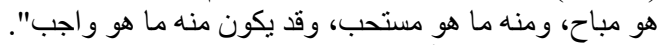

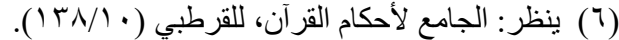

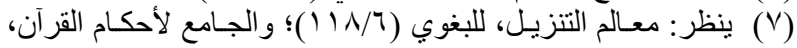
اللقرطبي (1/ (1) (1) ).

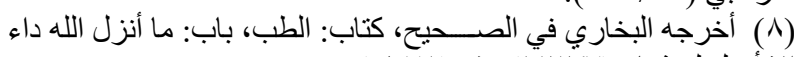

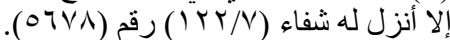

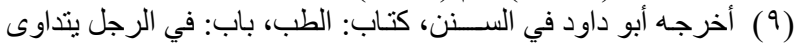

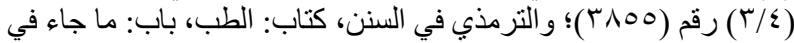

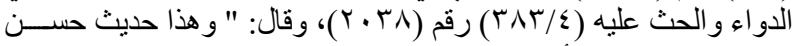

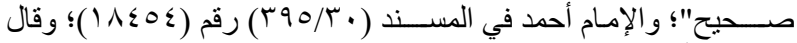
المحق الأرناؤوط : " إسناده صحيح ورجاله ثقات رجال الصحيحين".
الفحوصــــات والعمليـات الجراحيـة، أو الطبيعيـة أو فولئاه النفسية لأجل البرء من المرض بإذن الله تعالى. (')

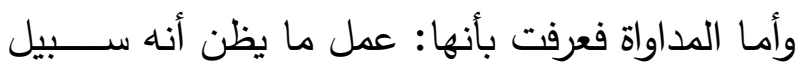

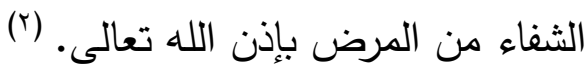

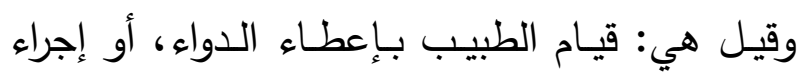

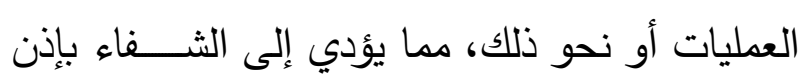
الله تعالى. (־) فعلى هذا: فالتداوي من جانب المريض، والمداواة من

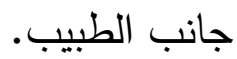
المسألكة الثانية: حكم التداوي:

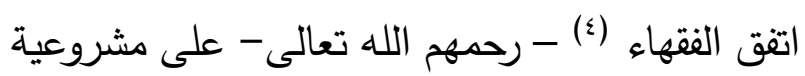

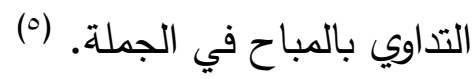
واســـتـلوا على ذلك من الكتاب والســــنة والإجماع

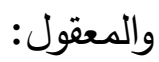

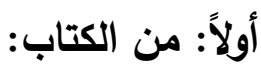

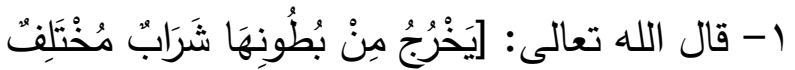

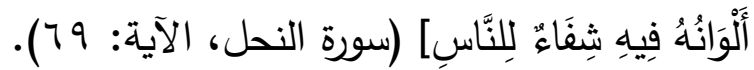

(1) بنظر : فقه القضـــايـا الطبيـة المعـاصــرة، للقرة داغي، والمحمدي

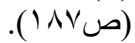

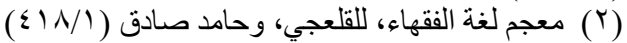

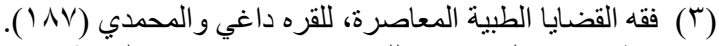

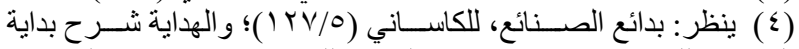

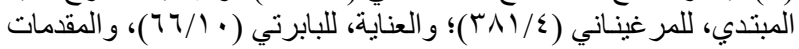

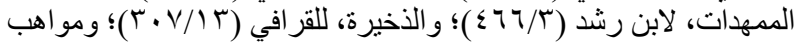

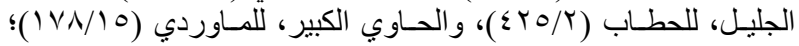

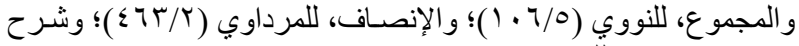

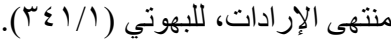

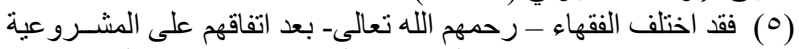

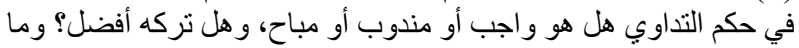

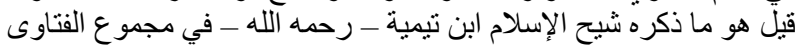


مما ســبق - في المبحث الأول- ذكر طرق التداوي والعلاج بزراعة فضــلات الأمعاء البشــرية تبين أنها ثلاثة طرق مختلفة، يجمع بينها بقاء أصـــل المـادة فيها وعدم تحولها أو تغيرها إلى شــــيء آخر يغير مادتها ولو أضيف لها مواد أخرى، ولمعرفة حكم كل طريقة ينبغي بيان حكم المســألة إجمالاً، ومن خلال اسـتقراء كتب الفقهاء المتقدمين - رحمهم الله تعالى إلى - لم أجد - فيما اطلعت عليه من مصــــادر - من تطرق إلى حكم التداوي بفضــــلات أو عذرة الآدمي مي ملي خاصـــــة، وإنمـا غـايـة مـا وجدت هو حكم التداوي بالمحرمات أو بالنجاسات. فعلى هذا يمكن تخريج المســـألة على حكم التداوي

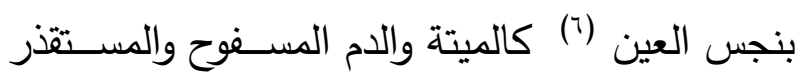
من البول أو الحشــرات وغيرها، ومن ثم معرفة حكم كل طريقة من الطرق الســـابقة في التداوي أو علاج البكتريا المقاومة للمضادات. المسألة الثانية: حكم التداوي بنجس العين: تحرير محل الخلاف: اتفق الفقهاء (V) - رحمه اللـه تعـالى - على أنـه يحرم التداوي بالنجاسـات إذا أمكن التداوي بغيرها من

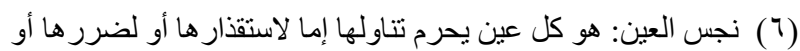

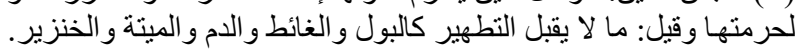

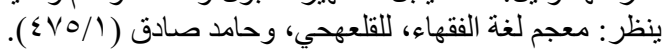

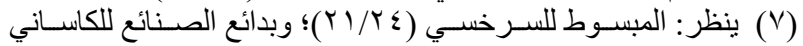

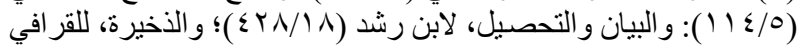

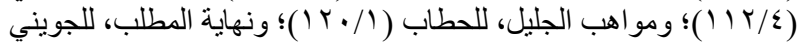

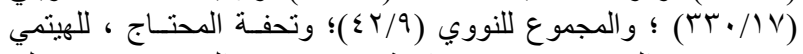

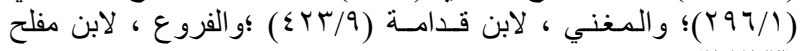

r- حديث جابر بن عبدالله - رضــــي الله عنهما-

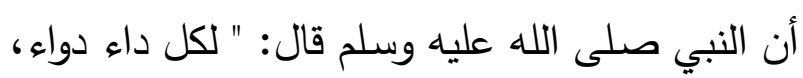

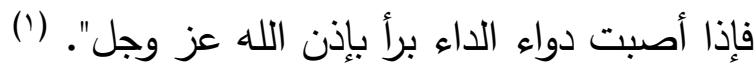
وجه الالالة من الأحاديث: دل مجموعها على إخبار النبي صلى الله عليه وسلم بأن لكل داء شـفاء وفي ذلك ترغيب في طلب الدواء

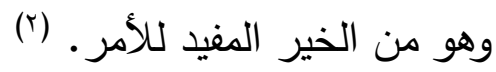
ثالثاً: من الإجماع: من الخيز العغن حكى بعض أهـل العلم الإجمـاع على مشـــروعيـة التداوي. (r)

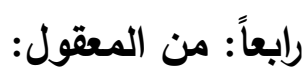
أن التداوي مظنة المصلحة وهي الثفاء، ومن المعلوم

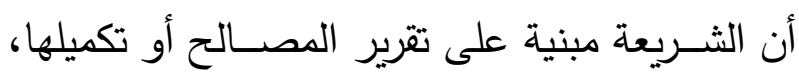

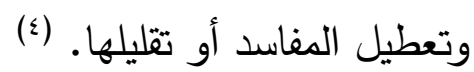

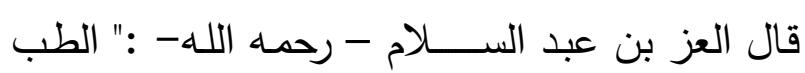
كالشرع، وضع لجلب مصالح السلامة والعافية ولدرو

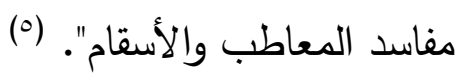

المطلب الثـاني: حكم مـداواة البكتربـا المقــاومــة (C.difficile) وفيه ثلاث مسائل: المسألة الأولى: تأصيل المسألة:

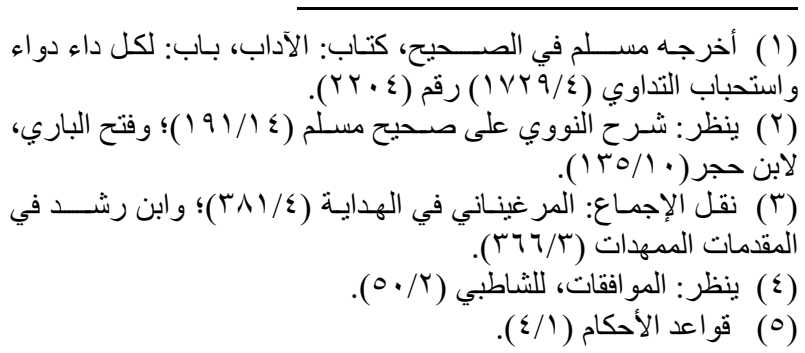


ثانياً: عموم الأدلة الدالة على تحريم النجاســـات، ويدخل في ذلك التداوي بها، ومنها : قوله تعالى: [حرمت عليكم الميتـة واللدم ولحم الخنزير] (ســــورة

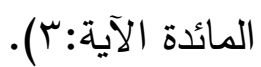
واختلف الفقهاء - رحمهم اللـه تعـالى - في حكم التداوي بالنجاسـات لباطن البدن (بالأكل والثــرب) للحاجة أو الضرورة على ثلاثة أقوال:

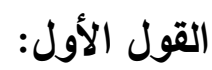
تحريم التداوي بالنجاسات لباطن البدن مطلقاً، وسواءً كانت النجاسـة خالصـة أو مختلطة بغيرها (0)، وبهذا القول قـال جمهور الفقهـاء من بعض الحنفيـة(؟)،

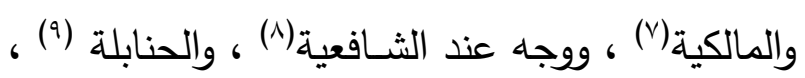
واختاره شيخ الإسلام ابن تيمية(·) ، وتلميذه ابن القيم

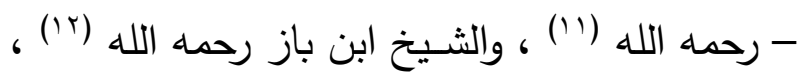

المباحات (أي بلا حاجة ولا ضــــرورة) لباطن البدن وظاهره. واستدلوا بما يأتي: واهره

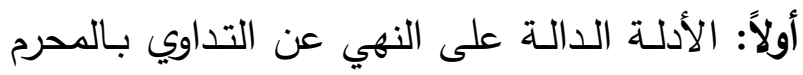

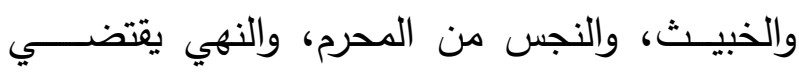
التحريخ. (1) ومنها ما يأتي: - حديث أم سـلمة - رضـي الله عنها - أن النبي

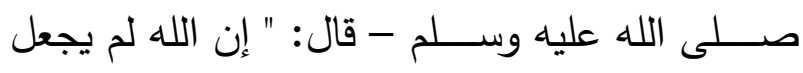

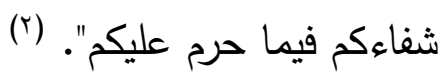
r- حديث أبي الدرداء - رضـي الله عنه - أن النهي

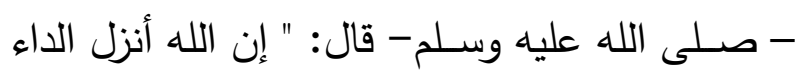
والدواء، وجعل لكل داء دواء، فتداووا ولا تتـداووا

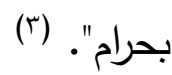
r- حديث أبي هريرة - رضي الله عنه - قال: " أن النبي صـلى الله عليه وســلم نهى عن الدواء الخبيث

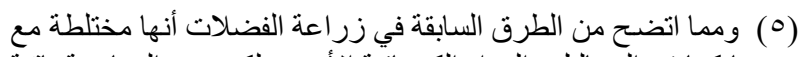
غير ها كما في المحاليل و المو اد الكيميائية الأخرى لكن عين الكئل النجاسـة باقية

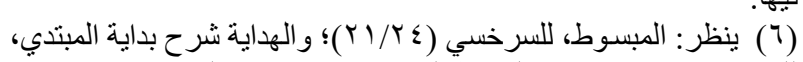

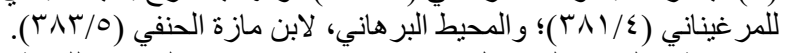

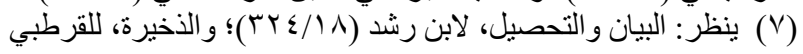
( $(Y \cdot T / K)$

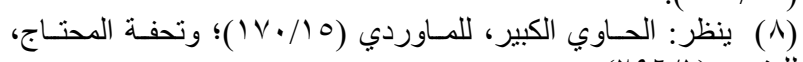

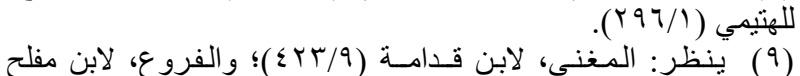
. (r $(r / T)$

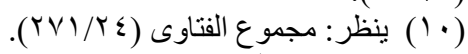

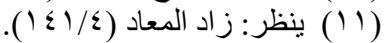

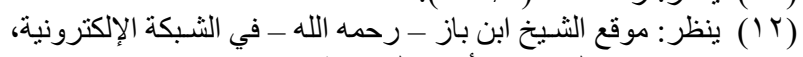

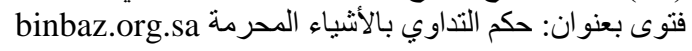

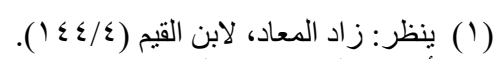

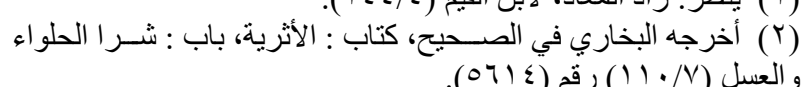

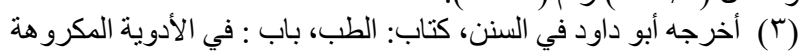

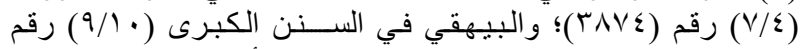

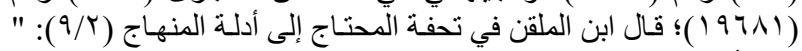

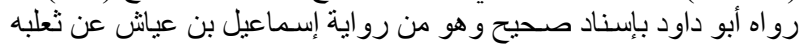

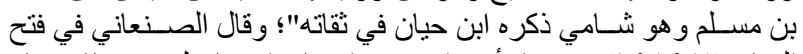

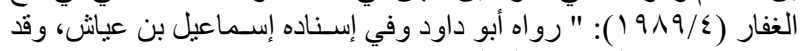

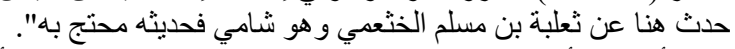

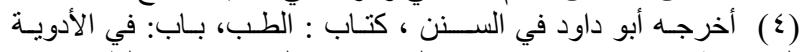

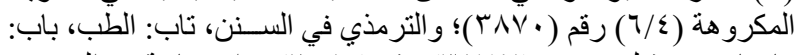

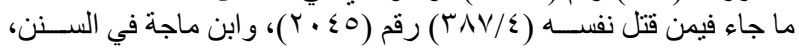

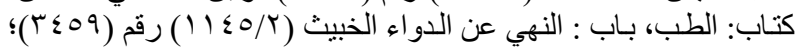

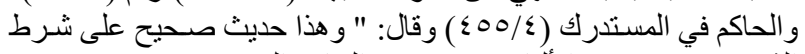

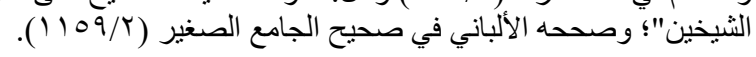


ץ- عموم الأدلة - السـابقة (') - الدالة على تحريم

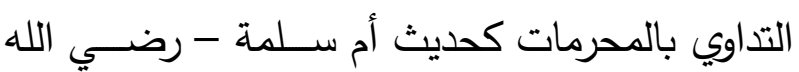

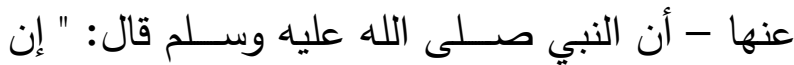
الله لم يجعل شفاءكم فيما حرم عليكم". (ri)

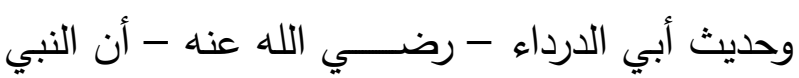

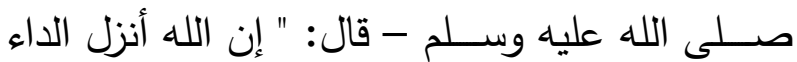
والـدواء، وجعل لكل داء دواء، فتـاووا ولا تـداووا

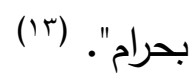
وجـهـ الــلالــة: دل الحديثـان على تحريم التداوي بالمحرم؛ إذ الحديث الأول فيه نفي لوجود التداوي في المحرم، والثاني فيه نهي عن التداوي بالحرام، فدل

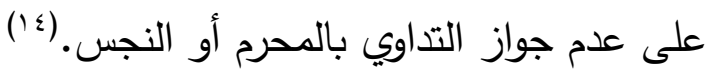

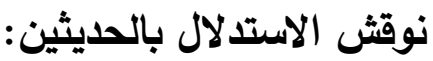

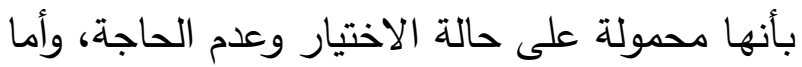
في حال الضرورة فلا يكون حراماً كالميتة. (10) أجيب عن المناقشة من وجهين(1') : الأول: أنه لا ضرورة للدواء، لأنه لا يقين الشفاء فيه.

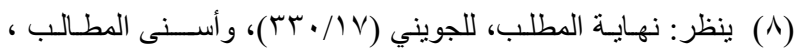

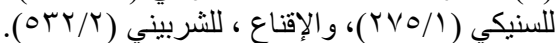

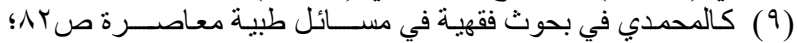

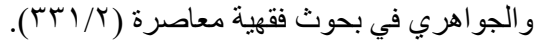

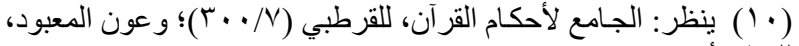

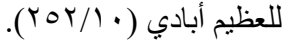

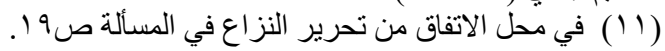

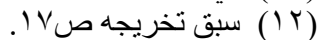

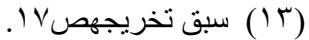

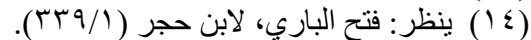

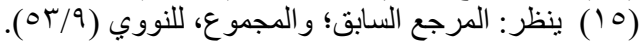

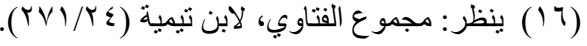

والثــيخ ابن عثيمين (') ، ومـا عليـه فتوى اللجنـة

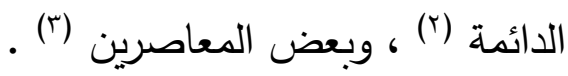
القول الثاني: جواز التداوي بالنجاسـات لباطن البدن

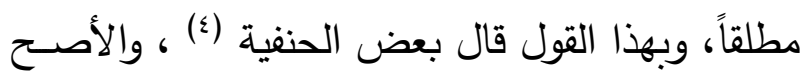

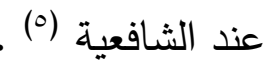

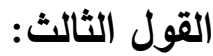
جواز التداوي بالنجاسـات إذا تيقن طريقاً للثـفاء ولم يوجد غيره من المبـاحات والا فلا يبـاح، وبـه قـال:

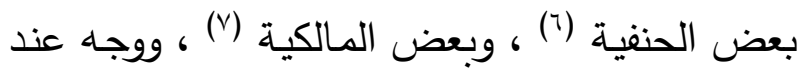

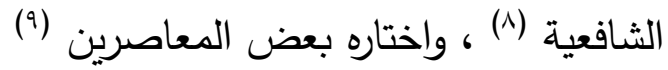

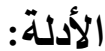

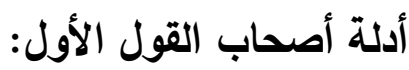

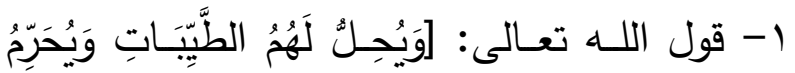

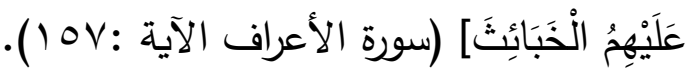

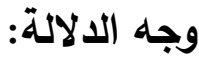
أن الآيـة تدل على تحريم الخبائث وهي المحرمـات بالثـــرع ومن القاذورات، والتحريم عام ويدخل فيه

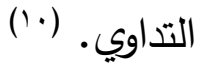

(1) ينظر: الموقع الرســمي للثــيخ ابن عثيمين رحمـهـ اللـه. binothaimeen.net

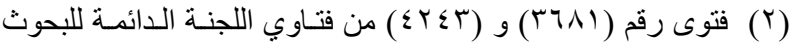
العلمية و الإفتاء.

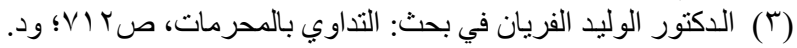

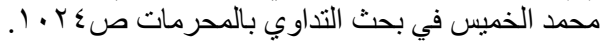

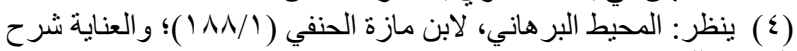

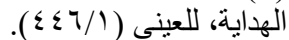

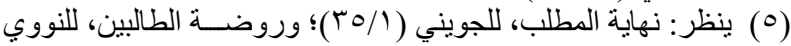

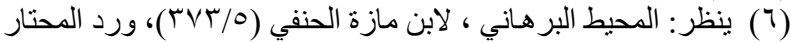

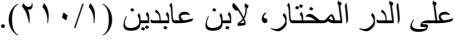

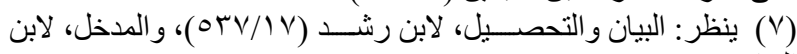

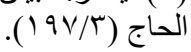


0- إنمـا حرم على الخبيث هذه الأمسة حميًّة لهم،

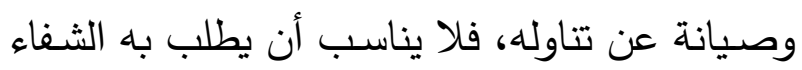

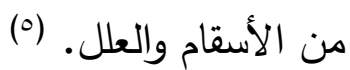
أدلة أصحاب القول الثاني:

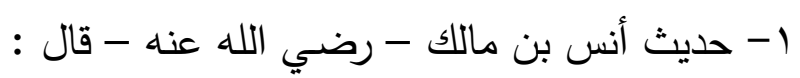

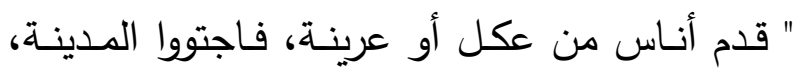
فأمرهم النبي صلى الله عليه وسلم بلقاح وأن يشربوا

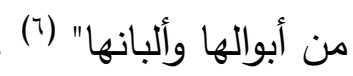

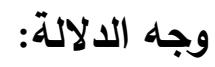
أن النبي - صــلى الله عليه وســلم - أباح للعرنيين

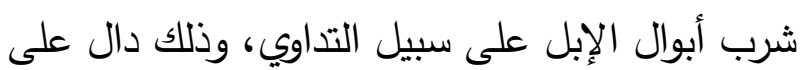
أن النجاسات يحل التداوي بها (v) . ץ- قياس التداوي بالمحرمات والنجاسـات على إباحة

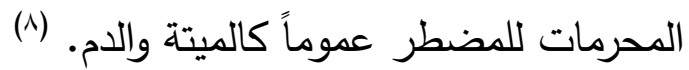

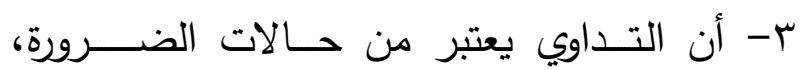
والضـــرورات تبيح المحظورات، كما في قوله تعالى:

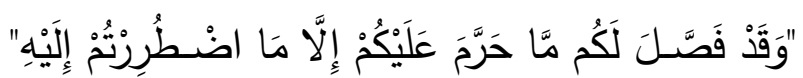

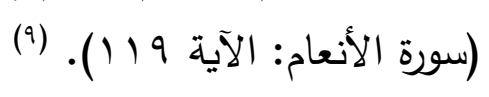

نوقش الاليلان الثاني والثالث من أوجه:

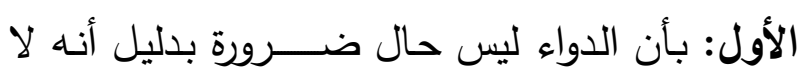

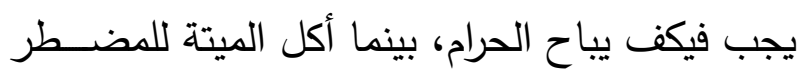

$$
\text { واجب. (1.) }
$$

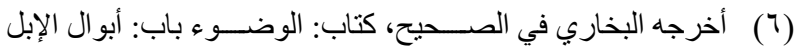

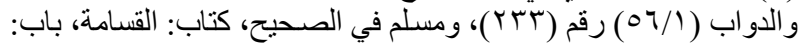

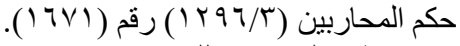

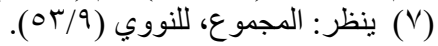

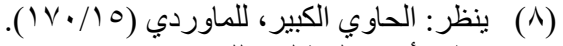

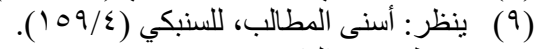

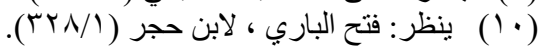

الثاني: أن المرض ليس ضـــرورة تبيح المحرم؛ لأنه

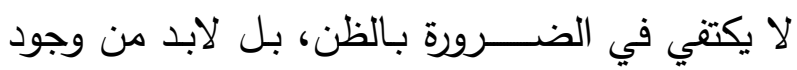
حقيقتها. يمكن أن يُرد على ذلك: بأن هناك غلبة ظن لتحقيق الثـفاء وتقدير الضــرورة فيما إذا قدر الأطباء الثقة في ذلك أن المريض قد وند يهلك إذا لم يأخذ هذا الدواء. r- حديث أبي هريرة - رضــي الله عنه - أن النبي

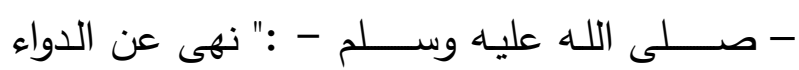

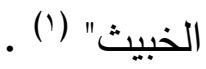

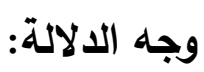
النهي عن الدواء الخبيث، والخبث يطلق وقد يراد بـه

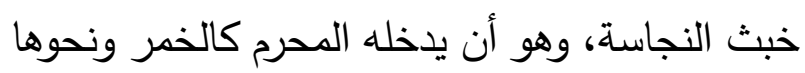

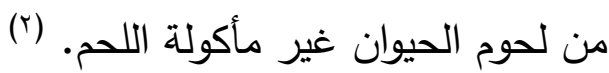
نوقش الاسـتلال : بأن الحديث محمول على النهي عن التداوي بالمسـكر وعلى التداوي بالحرام من غير بـ

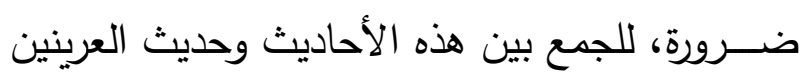

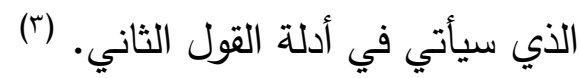

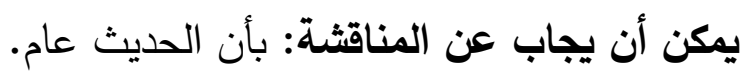

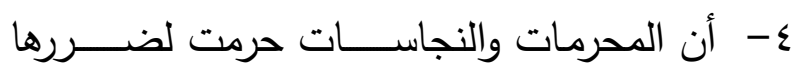
الديني والجسدي، والضـرر لا يزال بمثله، ولا بما هو

أشد منه. (ई)

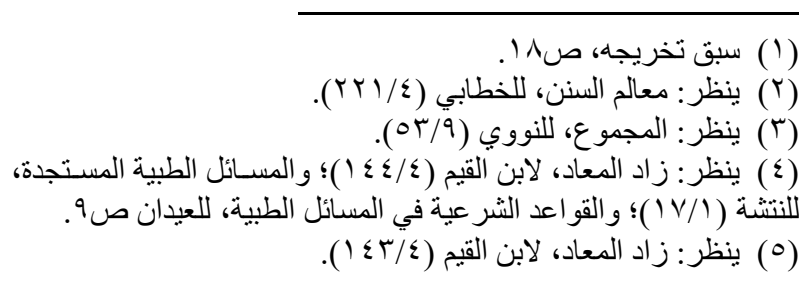


- أدلة أصـــــاب القول الأول - في التحريم ظاهرة وصريحة، وأن الله تعالى لم يجعل الثفاء في الخبيث أو الحرام، وكما قال الإمام ابن القيم - رحمه الله - "فإن تحريمه يقتضــي تجنبه والبعد عنه بكل طريق،

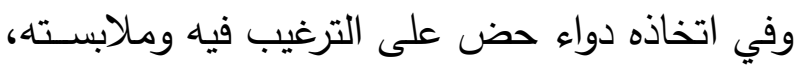

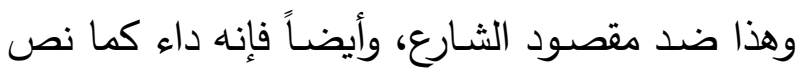
عليه صـــاحب الثـــريعة فلا يجوز أن يتخذ دواءً، وأيضاً فإنه يكسب الطبيعة والروح صفة الخبث، لأن

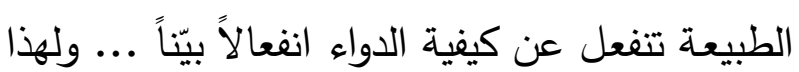

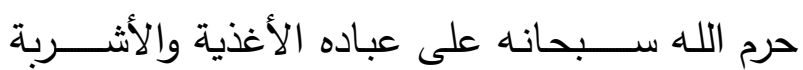
والملابس الخبيثة" (†). لكن قد يُقـال أن هذا على العموم، وأن الدواء في

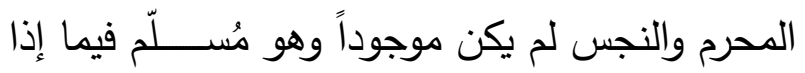

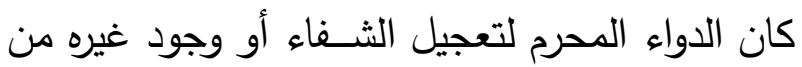
المباحات، أما مع تطور العلم والطب وإمكان وجود

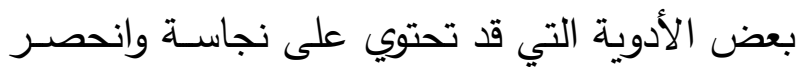

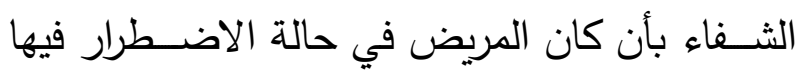

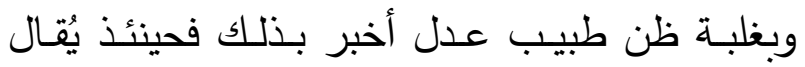
بالإباحة لدفع الضرر ، وبقدر هذا الضرر •

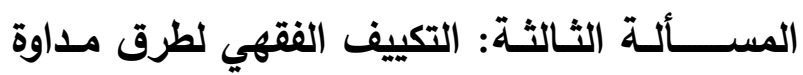
البكتيريا (C.difficile) بزراعة الفضـلات البثــرية :(FMT)
الثاني: أن المضــطر يحصـل مقصــوده يقيناً بتناول

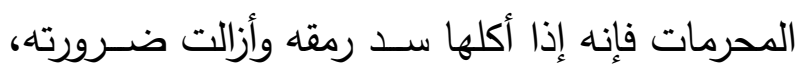
وأما الخبائث بل وغيرها فلا يتقين حصول الشفاء بها فما أكثر من يتداوى ولا يشفى. (')

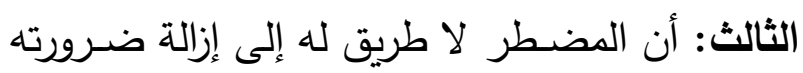

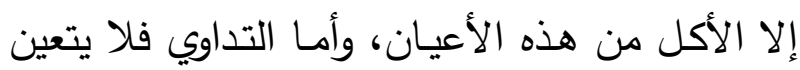
تناول هذا الخبيث طريقاً لشفائه فإن الأنواع كثيرة وقد

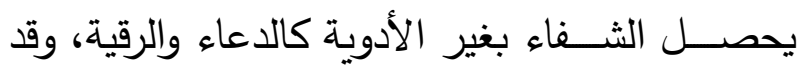
يحصـل الثـفاء بغير سـبب اختياري، بل بما يجعله الله في الجسم من القوى الطبيعية ونحو ذلك. (؟) أدلة أصحاب القول الثالث: 1 - حديث أنس بن مالك الســابق (). من أن النبي

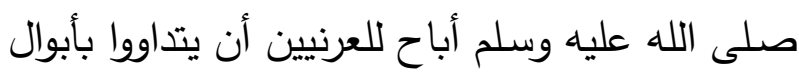

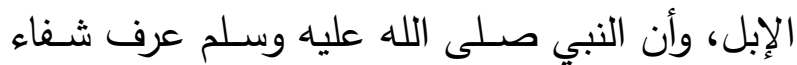
أولئك بها على الخصــوص، ولذا قالوا بجوازه عندما

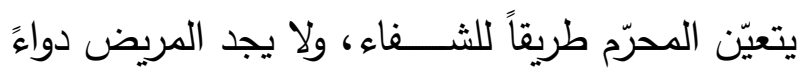

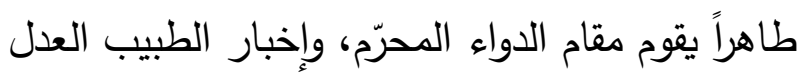
العارف. (๕) r- عدم قيام ما يقوم غيره من المباحات، فيباح لدفع

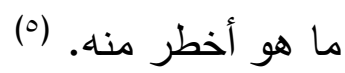
الراجح:

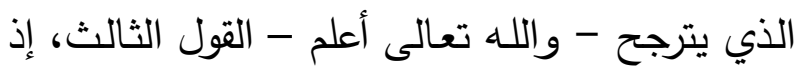
مقتضـاه الجمع بين الأقوال فما لا شكك فيه أن الأدلة

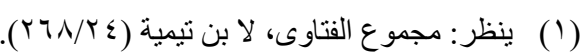

$$
\begin{aligned}
& \text { (Y) (Y) بنظر : المرجع السابق. }
\end{aligned}
$$

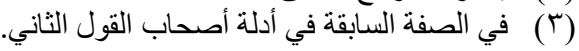

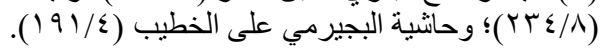

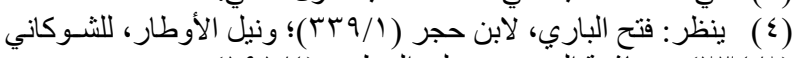


والضـــرورة الطبيـة هي: حالـة ملجئة يخاف معهـا الضـرر غالباً تسـتـعي تدخل حاذق كثـفاً وعلاجاً

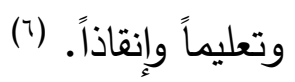

أو هي: حال يتعرض فيها المريض لضــــرر شــديد

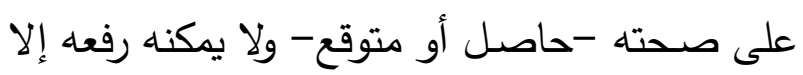

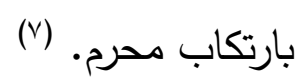
فإذا ما وجدت هذه الحالة، فإنه يجوز أن تدفع هذه به الضرورة حتى لو بارتكاب المحظور .

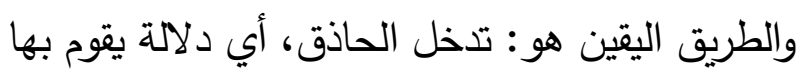

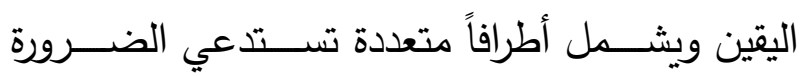

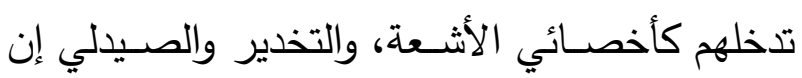

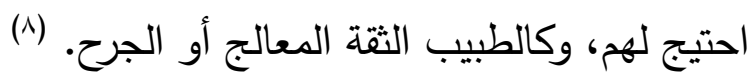

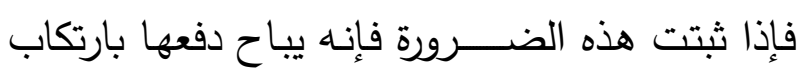

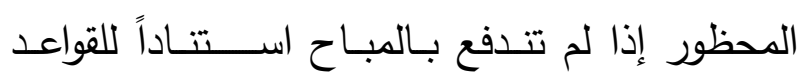

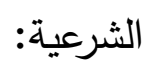

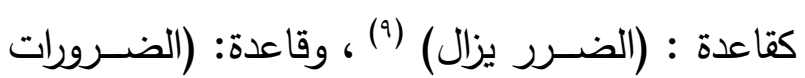

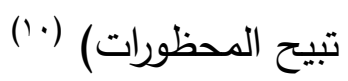

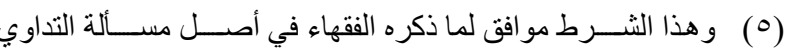

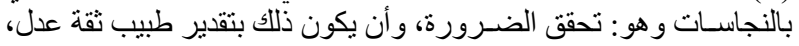
و هو المر اد بالطريق اليقين. (7) ينظر : بحث: مفهوم مصطلح الضرورة بين الثرع و الطب، للجلعود ص ص ו ו

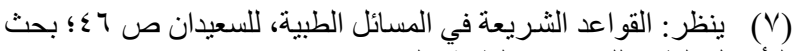
التأصيل الطبي للضرورة الطبية، الجابر ص الطبر 9. (^) ينظر : بحث: مفهوم مصطلح الضرورة بين الثر ع والطب، للجلعود ص r آ. (1) (9) ينظر : الأثــباه و النظائر، ،للسـيوطي ص به ؛ و الأثــباه و النظائر،

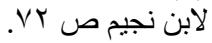

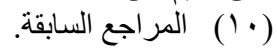

الطريقــة الأولى: كبســــلات الفم ومحلول أنبوب الأنف: أولاً: تبين في البحـث من النـاحيـة الطبيـة : أن الن

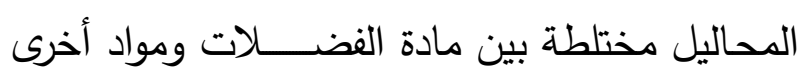

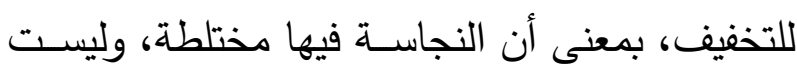
خالصـة لكنها موجودة ولم تتعدم، وإذا كان كذلك فإن لـان

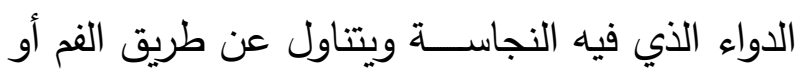

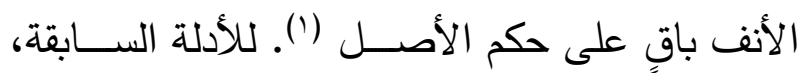
وتطبيقاً للقاعدة الفقهية (لا ضـرر ولا ضـرار) وقاعدة الاصن (الضرر لا يزال بمثله). (r) ثانياً: تبين - في المسألة السابقة - في حكم التداوي

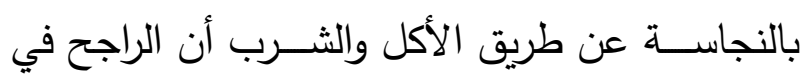

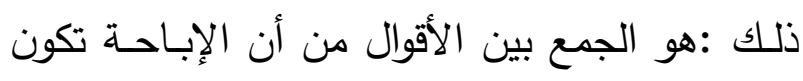

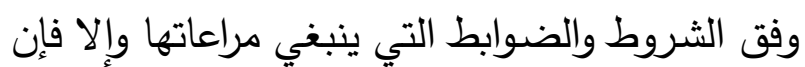
الأصل هو التحريم في التداوي بالنجاسة.

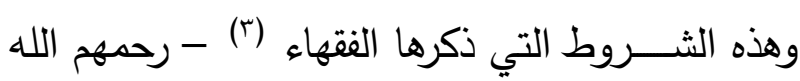
تعالى - من أجاز ذلك، وأضاف لها بعض أهل العلم

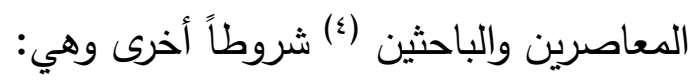
ا-قيام الضرورة وتحققها بطريق اليقين. (0)

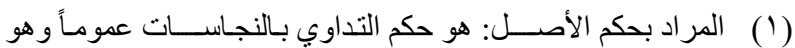

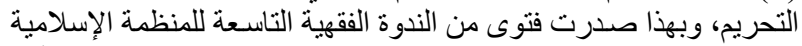

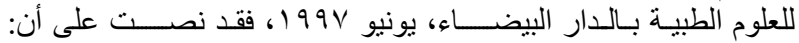

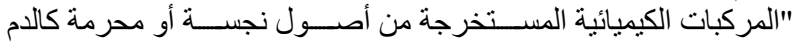

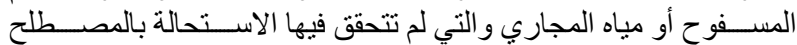

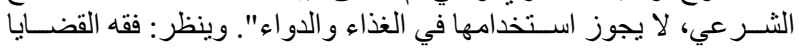

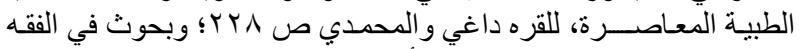
المعاصر ، للجو اهري (r/T/TrV)؛ و أما الحكم بالتفصيل فهذا ما سيتقرر في البحث فيما بعد.

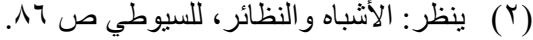

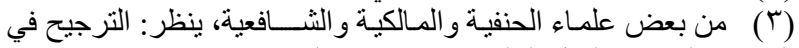

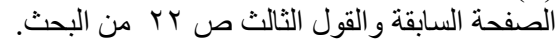

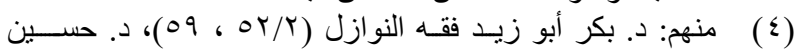

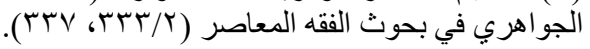


منفعة العلاج، أو كان البرء غير متيقن فإنه لا يجوز

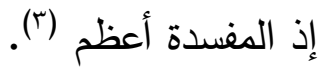

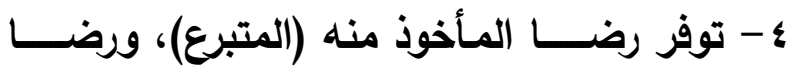

المنقول إليه أو وليه إن كان قاصراً:

ويشـــترط إذن المريض إذا كان تام الأهلية، أو وليه إذا كان قاصــراً، لأن رعاية كرامته حق مقرر له في الثـرع لا ينتهك إلا بإذنه، وهو المعمول باه عندنا بل في كل المرافق الصـحية، فلا بد من إذن الشـارع أولاً

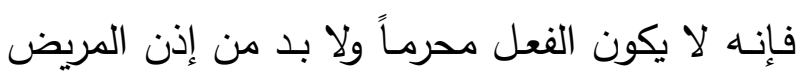
ثانياً إذا أمكن ذلك، إذ أنه يسـقط الإذن في الحالات الإســعافية الضـروريـة التي كون فيها المريض مهدداً بـالموت أو تلف عضـــــو من أعضـــــائهـ إذا لم يتم

إسعافه، ولا تسمح حالته الصحية بأخذ الموافقة. (ع) ه-سلامة المنقول منه، فينبغي التحقق من سلامته حتى لا يدفع الضرر بضرر أكبر منه.

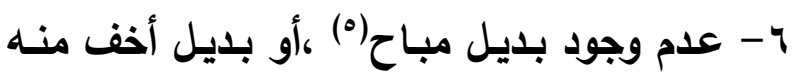
ضررً. قـال الإمـام ابن القيم - رحمـهـ اللـه - : "وقد اتقق الأطباء على أنه متى أمكن التداوي بالغذاء لا يُعدل

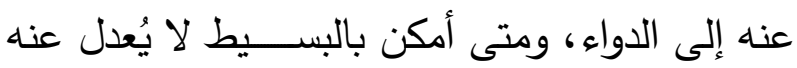

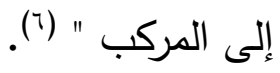

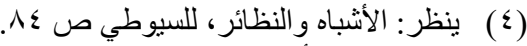

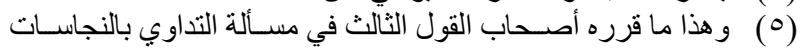
ص ب r من البحث.

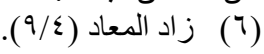

ومستتد هذه القواعد:

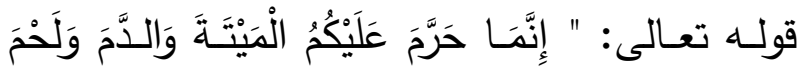

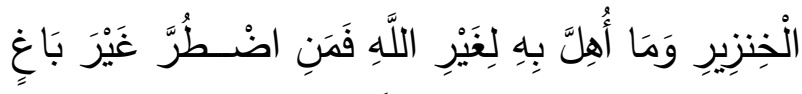

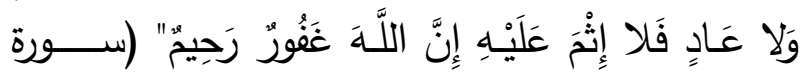

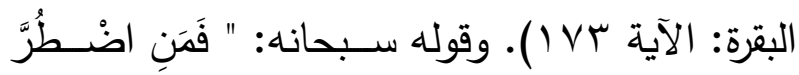

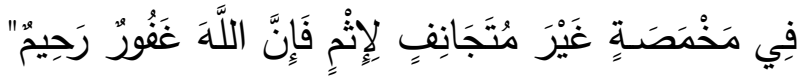
(ســورة المائدة: الآية ب). وهذا ليس على إطلاقه بل هو مقيد بالشرط أو الضـابط الثاني (الضرورات تقدر بقدرها) (') بأن r - أن تقدر الضـرورة بقدرها. وذلك اسـتناداً للقاعدة:

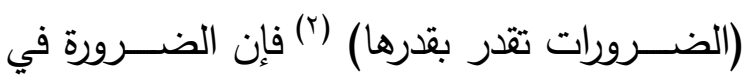
الثــرع وإن أبيح المحظور من أجلها إلا أن ذلك ليس على إطلاقـه، بـل هو مقيـ بــا تـدفع بـه الضــرورة ولا يزاد على ذلك، لقوله تعالى : "فَمَنِ

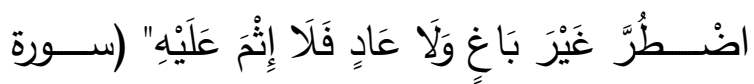

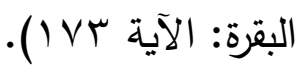
بمعنى: أن التداوي بالنجاســــة يكون قدر الإنقاذ من الهلكة وليس لتعجيل الشفاء. ب- غلبة الظن على نفع التداوي به: والمراد بذلك: أن يغلب على ظن الطبيب الثقـة نفع المريض وشــــــاؤه بهـذا الـدواء النجس حتى يقـال بالإباحة.

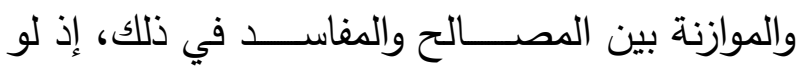
غابت مضـرة الدواء النجس أو الخبيث على مصـلحة

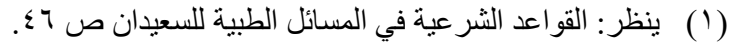

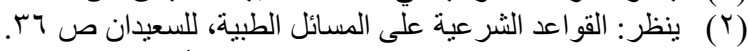

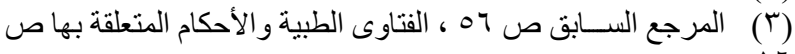


خلاصة ما سبق:

عند النظر لضــوابط القول بإباحة التداوي بالنجاسـة

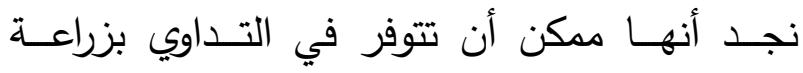

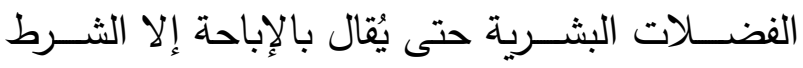

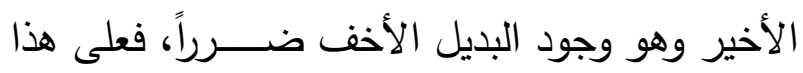

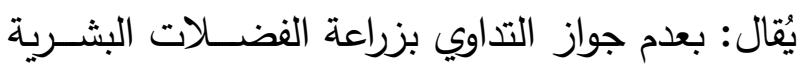

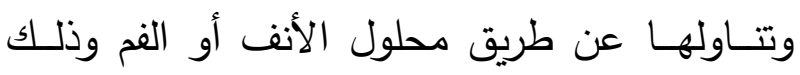

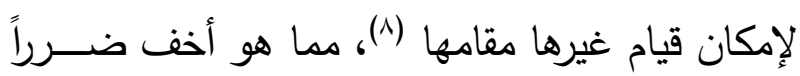

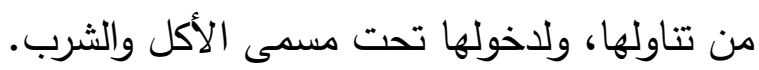
الطريقة الثانية: الحقن الثـــرجية ومحاول منظار القولون:

هـذه الطريقـة الأخرى من طرق علاج البكتيريــا

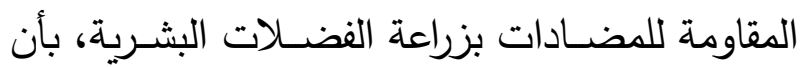

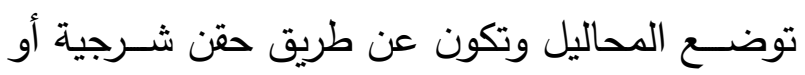

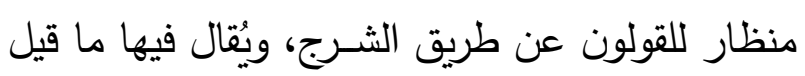
في الطريقة الأولى، إلا أنها تختلف في كون تناولها

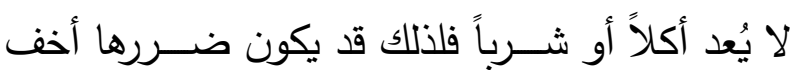

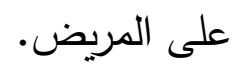

\section{وعلى هذا يُقال في خلاصة الحكم:}

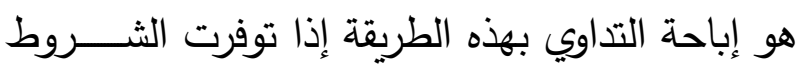
السـابقة، بأن يكون الضـرر متحقق على المريض إذا لها

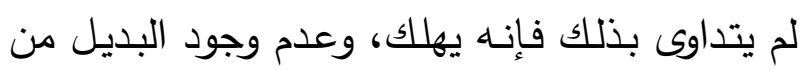

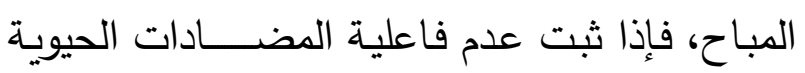

(7) بنظر : بحث: تطبيق القو اعد الفقهية على المسـائل الطبة، للمطرودي

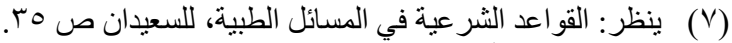

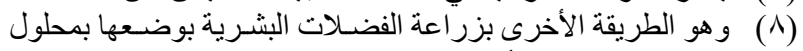
عن طريق منظار القولون أو الحقن الثرجية
وقد اتفق الفقهاء (')- رحمه الله تعالى - على أن

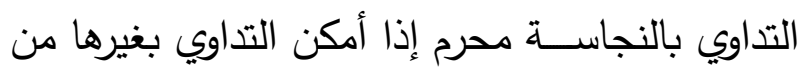

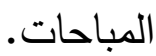

فعلى هذا يُقال في زراعة الفضلات البشرية :

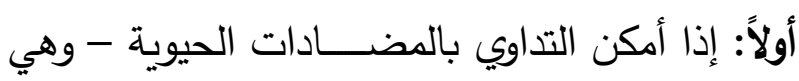
الطريقة الأولى بالعلاج (r)- فلا يُصـــار إلى المحرم

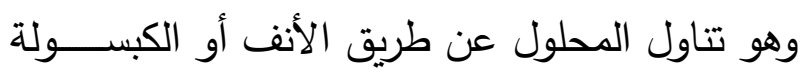
عن طريق الفم أو كذلك الحقن الشرجية.

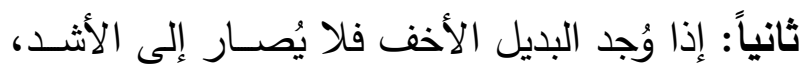

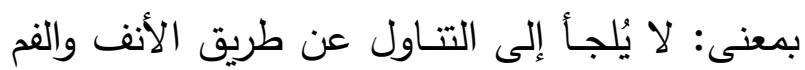
إذا وُجد البديل الأخف ضـــراً وهو الحقن الثـرجية.

اسـتــلاًً بالقاعدة: (الضـرر الأشــــــال بالضــرر الأخف) وقاعد: (يختار أهون الثــرين) (؛) وقاعدة : (إذا تعارض مفسدتان روعي أعظمهما ضرراً بارتكاب (أخفهما) (أذارض) فهذه القواعد تدل: على أن الضرر إذا كان لابد واقعاً

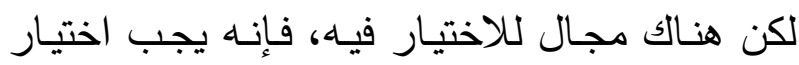

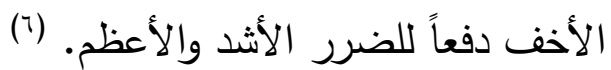
ولأن الثـــريعة جاءت بتقرير المصــــالح وتكميلها

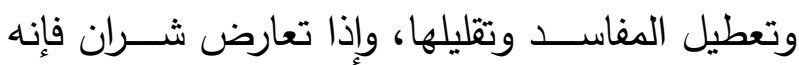
يختار أهونهما ويرتكب لدفع أشدهما. (v)

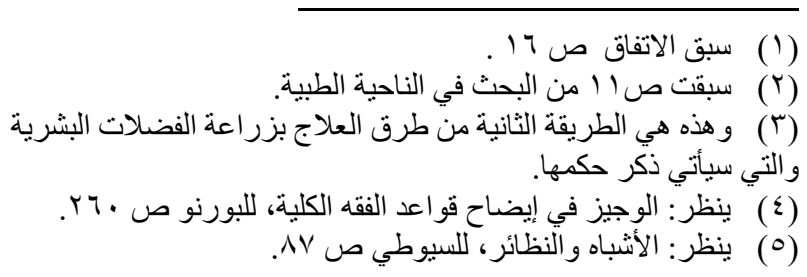




\section{الخاتمة}

الحمد لله الذي بنعمته تتم الصالحات، وفي ختام هذا البحث ظهرت نتائج عدة، من أهمها: 1- أن المداواة البكتريا المقاومة للمضـادات الحيوية طريقتان: الأولى: في المضــــــادات الحيوية. الثانية: زراعة الفضلات البشرية.

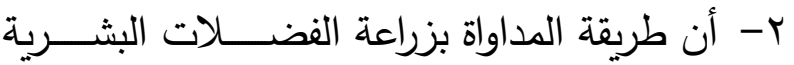

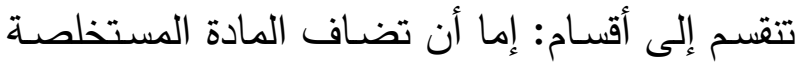
من الفضــــلات إلى محلول ملحي ويتم إدخالـه عن

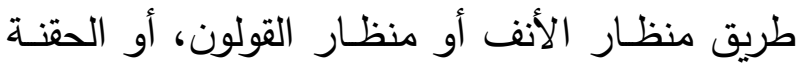

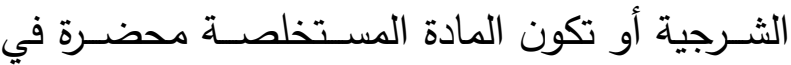
كبسولة وتتناول عن طريق الفم. r- الأصــل في مشــروعية التداوي الإباحة للأدلة على ذلك. ع- الأصـل في التداوي بالمحرمات والنجاسـات هو

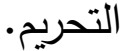
0- يختلف الحكم في المـاواة بزراعـة الفضــــلات البشرية باختلاف الطرق في ذلك.

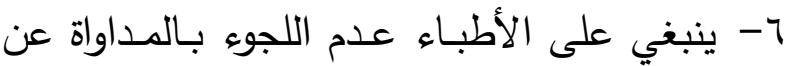
طريق زراعـة الفضــــلات إلا بعد فثـــــل المـداواة

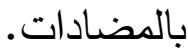
V- أن المداواة بزراعة الفضــلات البثــرية وتناولها عن طريق أنبوب الأنف أو كبسولة الفم محرم لوجود البديل الأخف منه ضرراً.

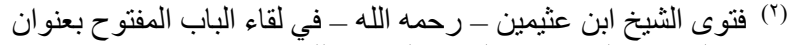
Binothaimeen.net حكم التداوي بالمحرم في الموقع الرسمي للثنيخ الثين :
الــــكورة (فـانكوميســيـن Vancomycin)، الميترونادازول (Metronidazole) ، فيداكسومسين (الريفاميكسـين (Fifaximin) ، (Fidaxomicin) فحينئذ يُقال: بجواز التداوي بهذه الحقن دفعاً للهلاك وتغليباً لجانب مصــلحة نجاة المريض على مفســـة أخذ النجاسة، مع تقدير الضرورة بقدرها. لكن مع ذلك هل يُقال بالضرورة للدواء النجس؟

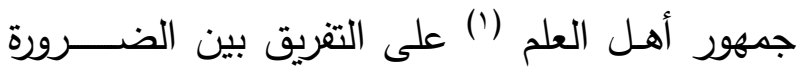

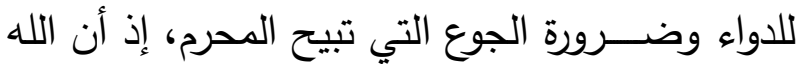
تعالى لم يحرم المحرم إلا ضـره، والضـرر لا ينقلب

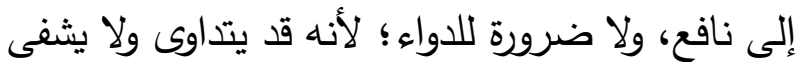
فلا تندفع الضـرورة، وقد يثـى بلا تداوٍ فلا نضطر إلى الدواء في هذه الحالة، لكن الجوع ضــــرورة فإذا خاف أن يموت وهو لم يأكل جاز أن يأكل الميتة، فإذا أكل زال عنه الموت، أما الدواء فلا ضرورة. (r) ففي هذه الحالة لا ضرورة.

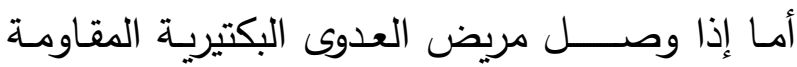
للمضـادات إلى حالة يخشى معها الهلاك بأن وصل الهل إلى حالة الضــــرورة بقول طبيب ثقـة- كمـا أفادت بعض الدراســـات الطبية ذلك- ولم يكن هنالك بديل مباح بأن لم يكن للمضادات فاعلية له، والدواء وثبتت لهن فاعلية زراعة الفضلات البشرية لنجاة المريض فحينئ يقال بالإباحة باســـتعمال هذه الطريقة وهي طريقة

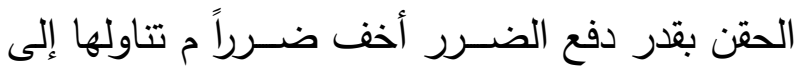
حين أن يوجد بديلاً عن ذلك. 
r- البدء بالعلاج البديل المباح من قبل المختصـين وعدم الثروع بالعلاج بالفضلات البشرية إلا في حال

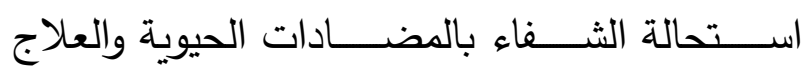

$$
\text { الكيميائي الآخر - الك. }
$$

ب- تقدير الضرورة بقدرها وعدم التهاون في ذلك وأن تكون إلى حين إيجاد البديل.

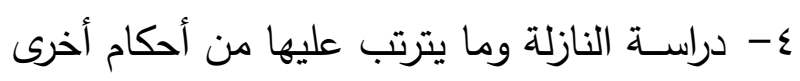

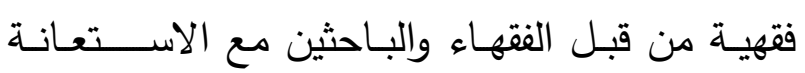
بالأطباء، إما بإقامة المؤتمرات أو البحوث المشتركة.
^- إباحة المداواة بزراعة الفضـلات البشرية وتتاولها

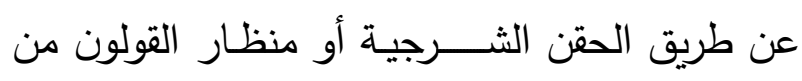

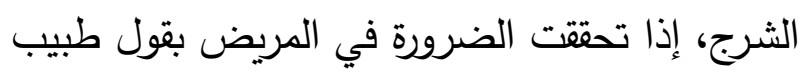

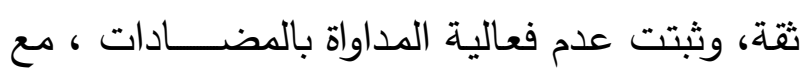
غلبة الظن بشفاء المريض، وبأن تكون بقدر نجاته. التوصيات: أهم التوصيات التي خرج بها البحث:

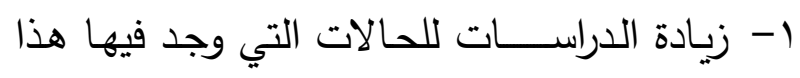
المرض طبياً خاصة في الدول العربية والإسلامية. الملحق

(a) قبل العلاج ب FMT
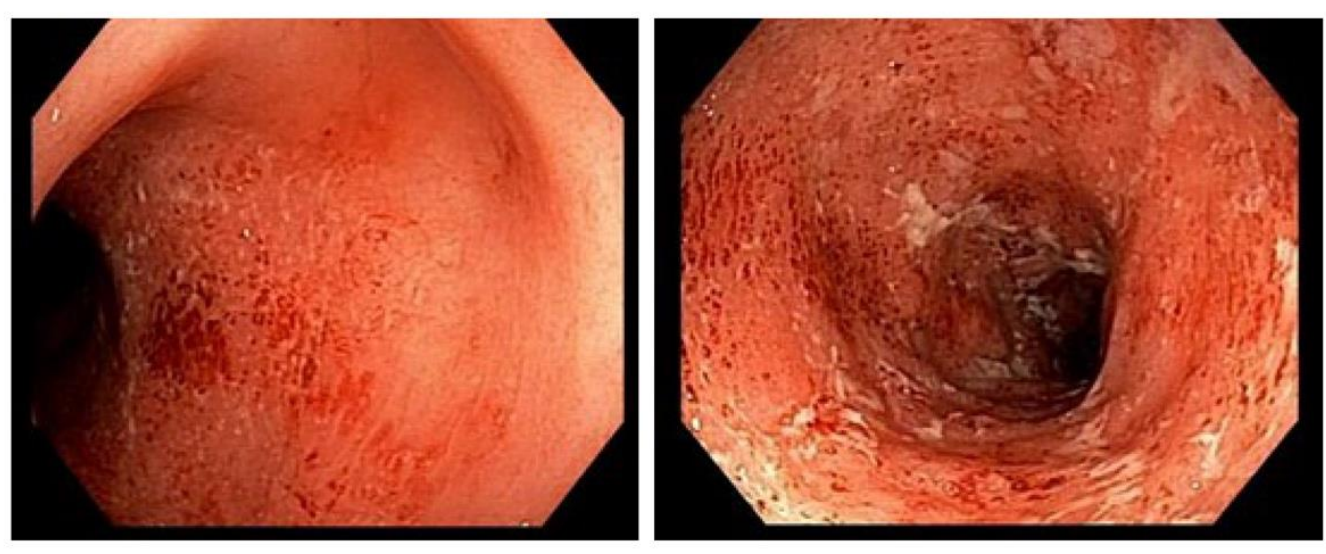

(b) بعد العلاج ب FMT 
صور توضيحية لقولون مريض مصاب بالالتهاب المزمن الذي أدى الى الإسهال. الصورتان الأولى قبل العلاجFMT ويظهر بها الالتهاب والتقرحات. الصورتان الأخيرتان تظهران شفاء القولون وذلك باختفاء الالتهاب والتقرحات بعد العلاج. المصدر :

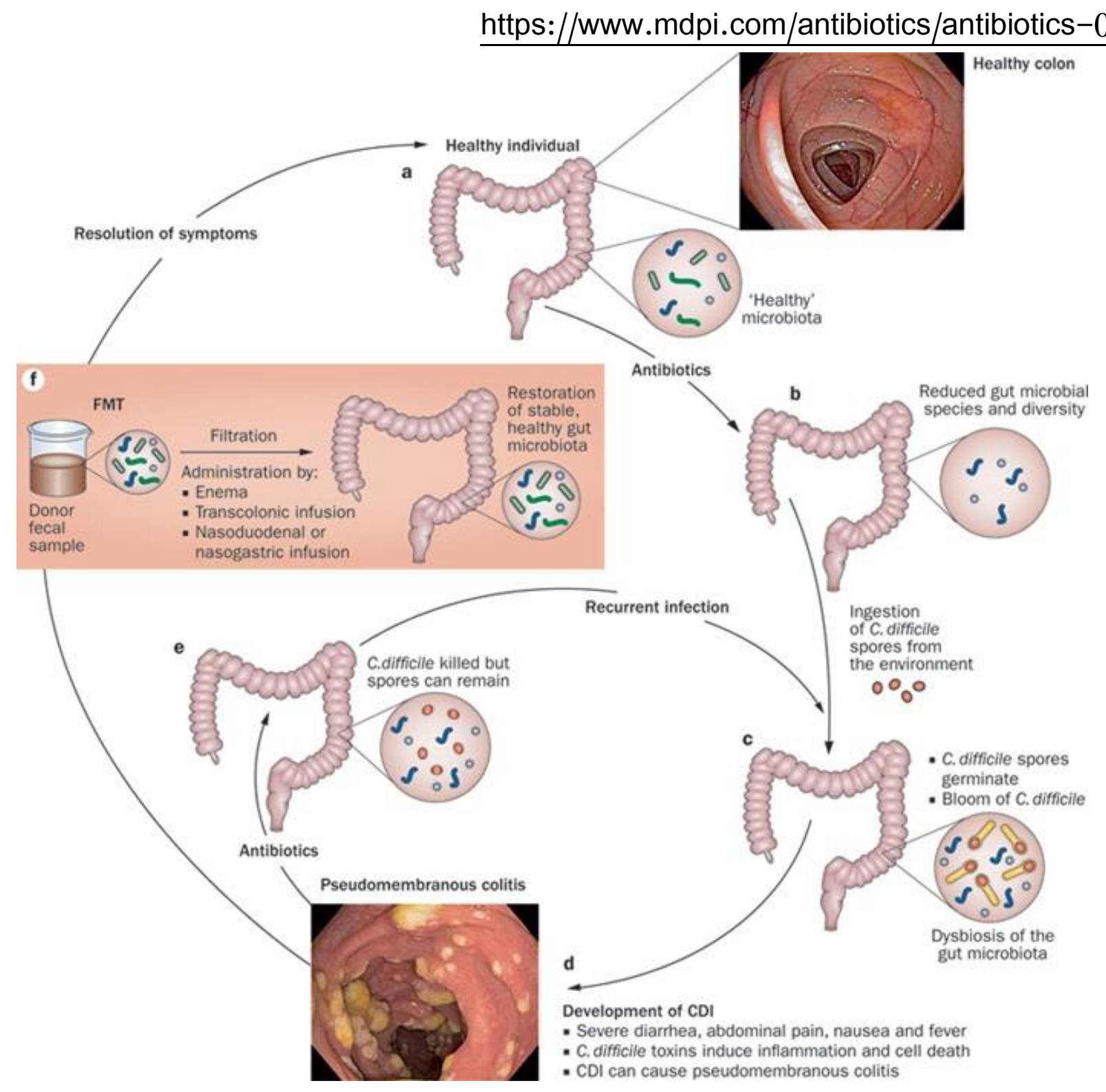

رسمة توضيحية لخطوات استخدام العلاج FMT تتضمن صورة لقولون ملتهب بالتهاب المزمن قولون سليم يحتوي على بيئة بكتيرية نافعة تساعده في مقاومة الأمراض

قولون تم علاجه بمضادات حيويـة لأمراض أخرى مما أدى الى تغير في البيئة الصحية نمو بكتيريا مقاومة للمضادات الحيوية في داخل القولون 


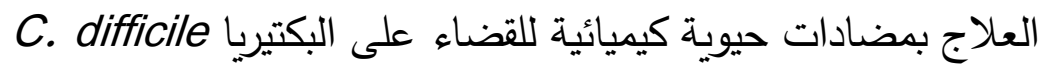

علاج القولون المصاب بالتهاب مزمن ومتكرر بالفضلات البشرية المعالجة FMT https://media.springernature.com/full/springer : المصدر

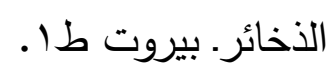

المراجع

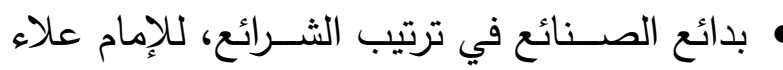

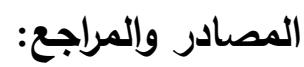

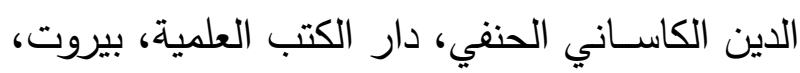

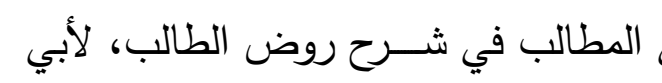

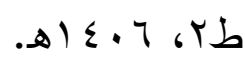

•البناية شرح الهداية، للعلامة أبو محمد محمود بن اهن

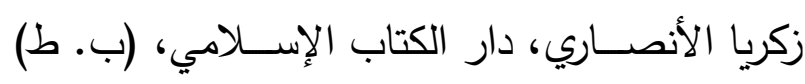

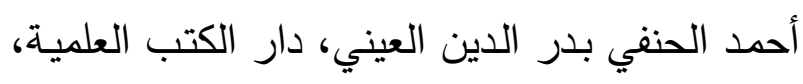

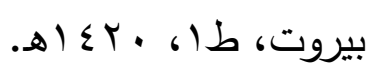
•البيان والتحصيل والثـرح والتوجيه والتعليل، لابن رشد القرطبي، تحقيق: د. محمد حجي وآخرون، دار

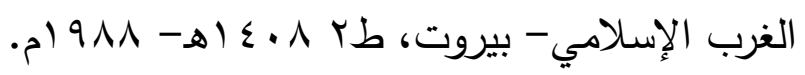

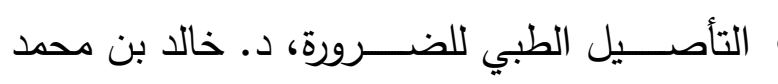

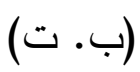

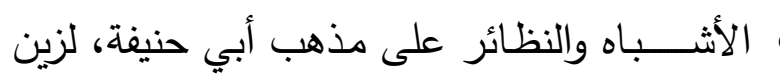

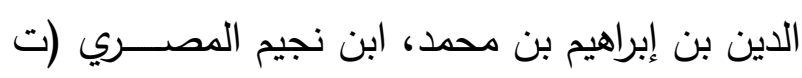

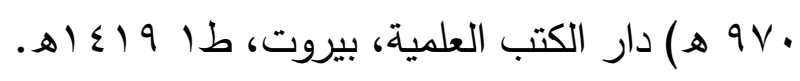

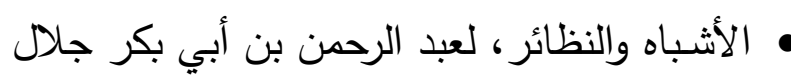

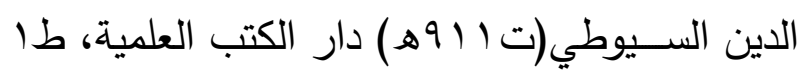

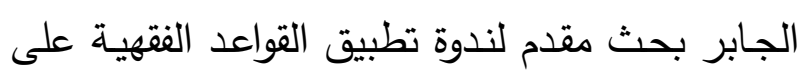

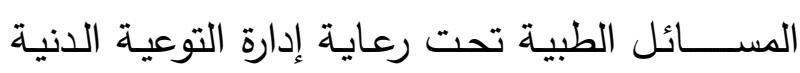

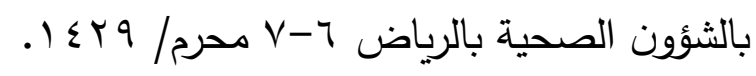

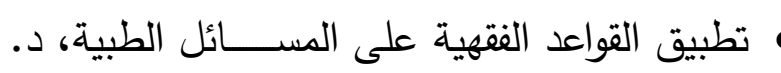
علي المطرودي، بحـث مقدم لندوة تطبيق القواعد الفقهية على المسائل الطبية تحت رعاية إدارة التوعية

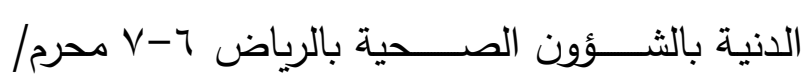

• تـاج العروس من جواهر القـاموس، لمحمـــــن

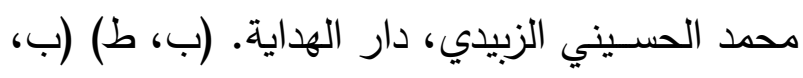
. () 211

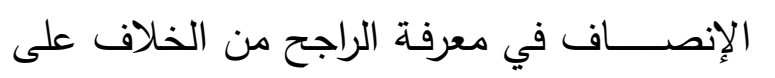

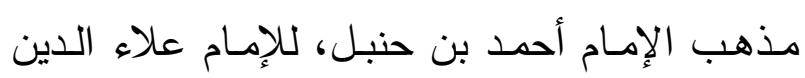

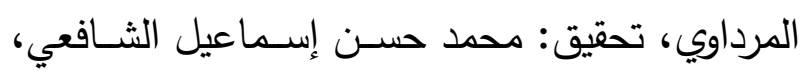

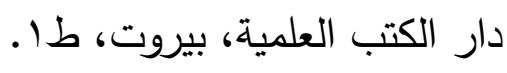

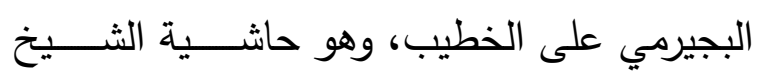

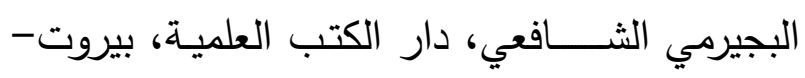

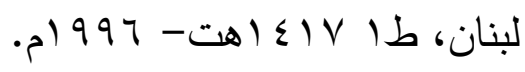
بحوث فقهية في مسائل طبية معاصرة، أ.د. علي

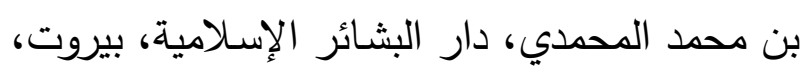
طا بن بحوث في الفقه المعاصر ، لحسن الجواهري، دار ت). 


\section{$.8 \leqslant$}

• زاد المعاد في هدي خير العباد، العلامة محمد بن

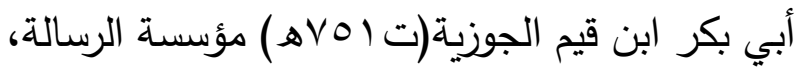

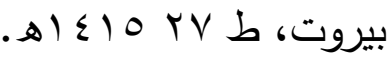
سـنن أبي داود، لأبي داود الســسـتاني، تحقيق: محمد محيي الدين عبد الحميد، المكتب العصـــريـة، صيدا، بيروت، (ب، ط) (ب، ت). ســن الترمذي، لأبي عيســى الترمذي، تحقيق: أحمد محمد شــــاكر ومحمد فؤاد عبد الباقي وإبراهيم عطوة، شركة مكتبة ومطبعة مصطفى البابي الحلبي،

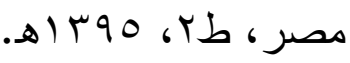
الســنـن الكبرى، لأحمــ بن الحســـين أبو بكر البيهقي، تحقيق: محمد عبد القادر عطا، دار الكتب

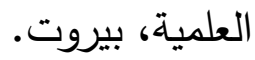
• ســنن النســائي، لأبي عبد الرحمن بن شــعيب النســــائي، تحقيق: عبــ الفتـاح أبو غـدة، مكتب المطبوعات الإسلامية، حلب، طب، 7 ، ؛ أهـ • شـرح منتهى الإرادات، لمنصــــور بن يونس رل

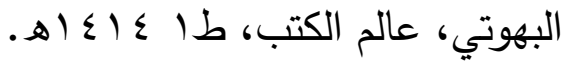
صـــحيح البخاري، للإمام محمد بن إســــماعيل البخاري، تحقيق: محمد زهير بن ناصـــر الناصـــر ،

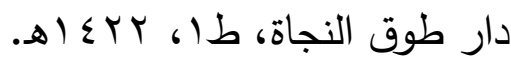
• صــــيح الجامع الصــــير وزيـاداته، لأبي عبد

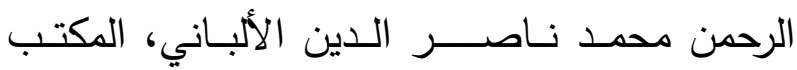
الإسلامي بيروت، (ب، ط) (ب، ت). صـحيح مسـلم بشـرح الإمام النووي، للإمام مسـلم
تحفة المحتاج في شـرح المنهاج، لأحمد بن حجر

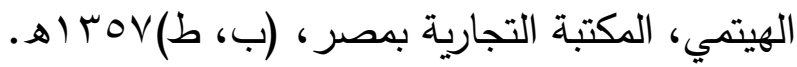
التداوي بـالمحرمـات، أ.د الوليد بن عبد الرحمن الفريان، بحث مقدم للمؤتمر الفقهي الإسـلامي الثاني الخاص بقضــــايا طبية معاصــــرة المنعقد بجامعة

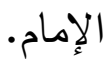
التداوي بالمحرمات، د. محمد بن سعود الخميس، بحث منشور في الثبكة الإككترونية. الجـامع لأحكام القرآن، لأبي عبد اللـه محمد بن أحمـد القرطبي، تحقيق: أحمــد البردوني وإبراهيم

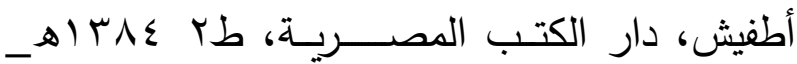
. $) 97 \leqslant$ • جامع الفتاوى الطبية والأحكام المتعلقة بها، جمع وترتيب: د. عبد العزيز بن عبد المحسن، دار القاسد

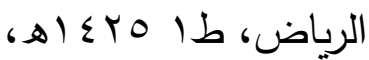
الحاوي الكبير في فقه مذهب الإمام الشـافعي وهو شـرح مختصــر المزني، لأبي الحســن الماوردي، تحقيق: علي محمـد معوض، وعـادل أحمـد، دار الكتب العلمية، ب روت، طا ، 19 1 (اهـ الذخيرة، لشــهاب الدين القرافي، تحقيق: محمد بو خبزة، دار الغرب الإسلامي طا ع9 99 (م. روضــة الطالبين وعمدة المفتين، للإمام أبي زكريا محيي الدين النووي، تحقيق: زهير الشاويش، المكتب الإسلامي، بيروت، طس، ب إع أهـ • رد المحتار على الدر المختار، لمحمد أمين بن

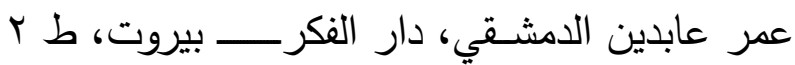


• قواعد الأحكام في مصــالح الأنام، أبو محمد عز

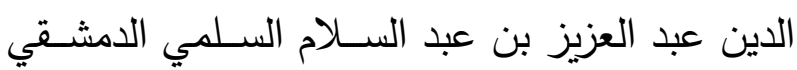
(ت • • آهـ) تحقيق: طه عبد الرؤوف ســعد، مكتبة

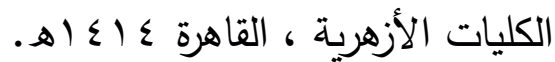
•القواعد الثـــرعية في المســــائل الطبية،د. وليد السعيدان، منشور في الثبكة العنكبوتية.

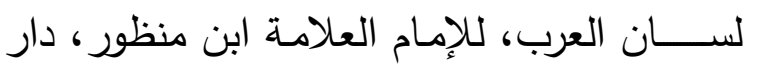

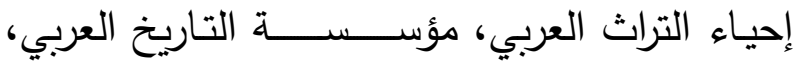

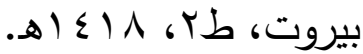

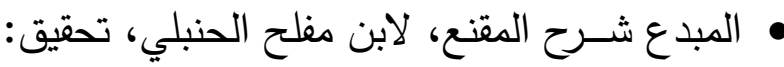

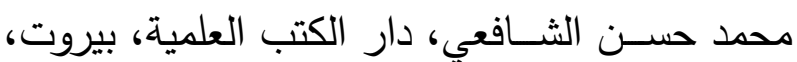

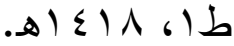
• المبســـوط، لمحمد بن أحمد الســـرخســي، دار المعرفة، بيروت، ط ع إ أهـ • المحيط البرهاني في الفقه النعماني، لأبي المعالي لفي الحنفي، تحقيق: عبـد الكريم الجنـدي، دار الكتب لـب

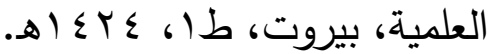

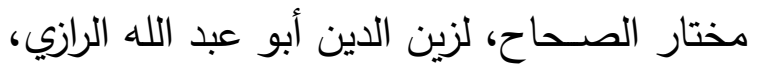
تحقيق: يوســف الثــيخ محمد. المكتبة العصــرية

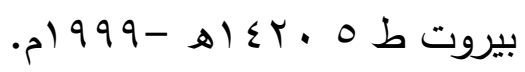

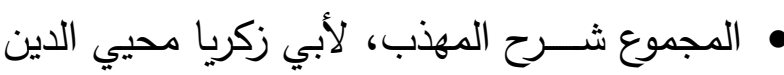
النووي، دار الفكر • • مجموع الفتاوى، لتقي الـين ابن تيميـة الحراني،

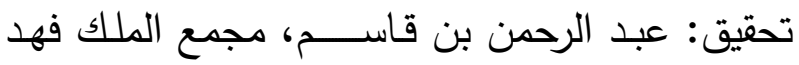

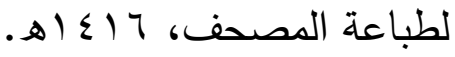
•المســائل الطبية المســـتجدة، د. محمد بن عبد
بن الحجاج النيسـابوري، دار الكتب العلمية، بيروت،

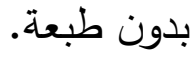
• العناية شـرح الهداية، لمحمد بن محمد بن شـمس الدين البابرتي، دار الفكر ، (ب، ط) (ب، ت).

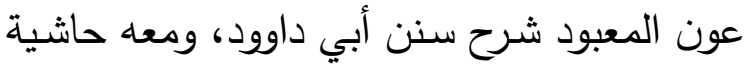

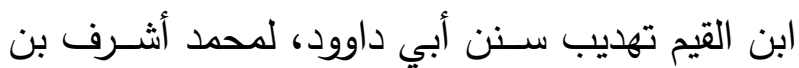

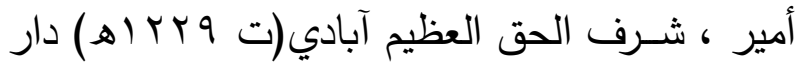

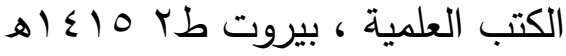
هتـاوى اللجنـة الدائمـة للبحوث العلميـة والإفتـاء، جمع وترتيب: أحمد بن عبد الرزاق الدويش، مؤسسـة

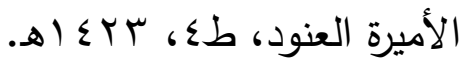
فقه القضـايا الطبية المعاصـرة، دراسـة فقهية طبية

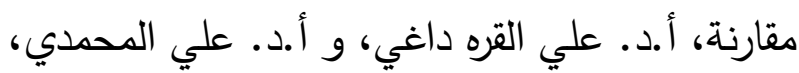

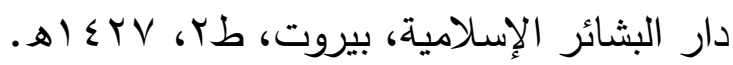

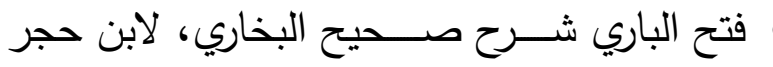

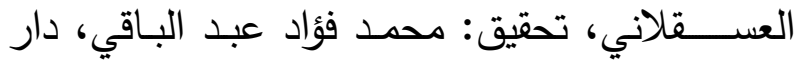

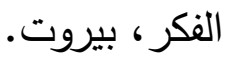

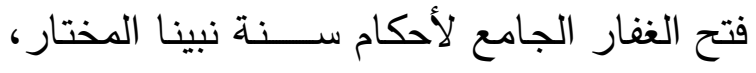

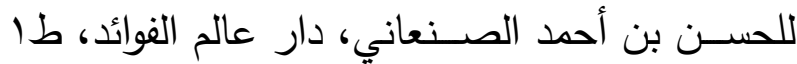
. $) \leqslant Y V$ • الفروع، لمحمد بن مفلح المقدسي، ومعه تصديح الفروع، تحقيق: د. عبد الله التركي، مؤسسـة الرسـالة . فقه النوازل، قضــايا فقهية معاصــرة، د. بكر بن

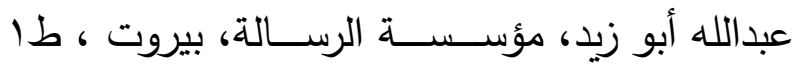
. $) \leqslant Y r$ 


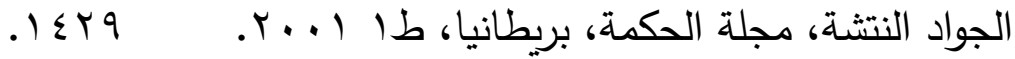

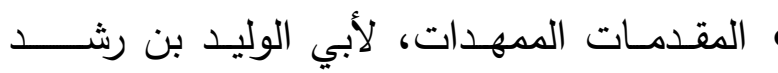

القرطبي، دار الغرب الإسلامي، طا م مـ اهـ.

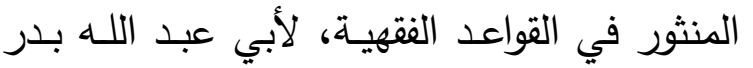

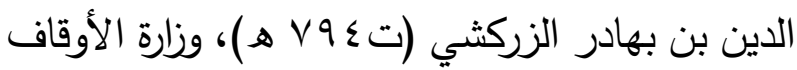
الكويتية، طץ 0. ـ اهـ. الموافقات، إبراهيم بن موسـى بن محمد الغرناطي

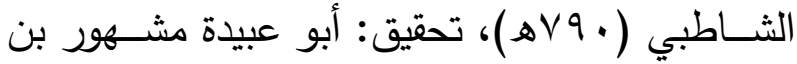

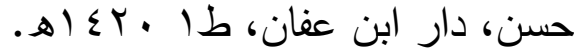
مواهب الجليل شرح مختصر خليل، لشمس الدين الحطاب المالكي، دار الفكر، طس، ب إع اله. • نهاية المطلب في دراية المذهب، لعبد الملك بن دابن

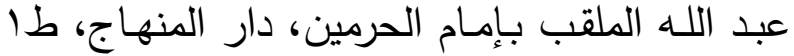
. ) $\leqslant$ 个人 ن نيل الأوطار، لمحمد بن علي الثـوكاني، تحقيق: عصام الدين الصبابطي، دار الحديث طا با سـ أهـ

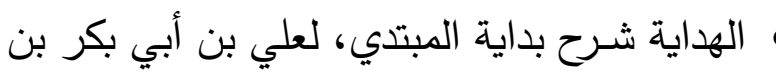

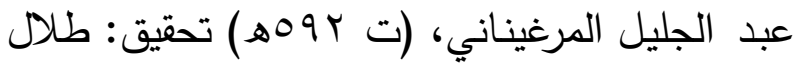
يوسـف، دار إحياء التراث العربي، بيروت، (ب، ط)

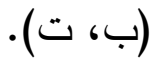
الوجيز في إيضـــــاح قواعد الفقه الكلية، د. محمد

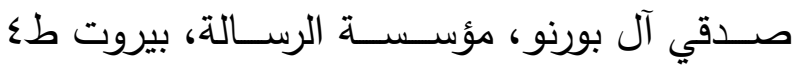
ه) 17

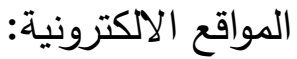
• موقع الثيخ ابن باز - رحمه اللهhttps://binbaz.org.sa ه المستدرك على الصحيحين، لأبي عبد الله الحاكم

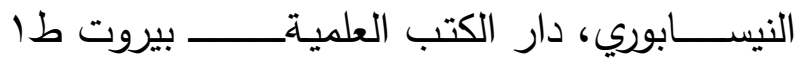
$.8) 11$ مسـند الإمام أحمد بن حنبل، لأبي عبد الله أحمد

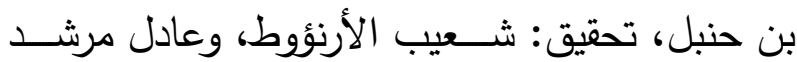

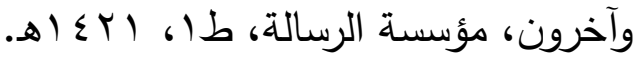

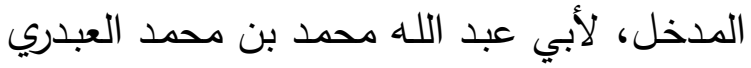
الفاسي الثهير بابن الحاج ( ت V ه هـ دار التراث،

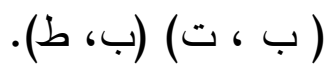
• معالم التنزيل في تقسـير القرآن، تفسـير البغوي،

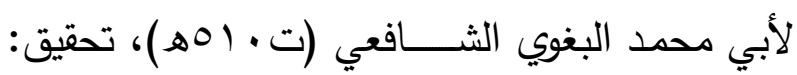
عبـد الرزاق المهـدي، دار إحيـاء التراث العربي،

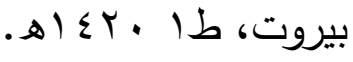
• معالم السـنن، وهو شـرح ســن أبي داوود، لأبي

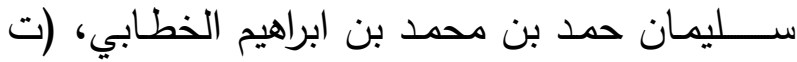

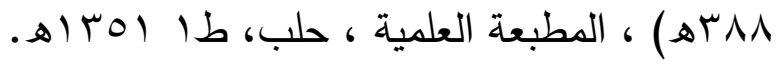
• معجم لغة الفقهاء، لمحمد رواس قلعهجي، وحامد صادق، دار النفائس، طץ ^1ـ الهـ. المغني لابن قدامـة، تحقيق: د. عبد الله التركي ومحمد عبد الفتاح الحلو، هجر للطباعة والنشـــر ،

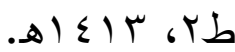
مفهوم مصــلح الضــرورة بين الثــرع والطب، دد عبد الرحمن الجلعود، بحث مقدم لندوة تطبيق القواعد الفقهية على المسائل الطبية تحت رعاية إدارة التوعية

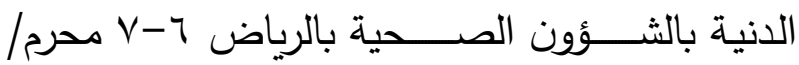




\section{المراجع الأجنبية}

Aas, Johannes, Charles E Gessert, and Johan S Bakken. "Recurrent Clostridium Difficile Colitis: Case Series Involving 18 Patients Treated with Donor Stool Administered Via a Nasogastric Tube." Clinical infectious diseases 36, no. 5 (2003): 580-85.

DeFilipp, Z., P. P. Bloom, M. Torres Soto, M. K. Mansour, M. R. A. Sater, M. H. Huntley, S. Turbett, et al. "Drug-Resistant E. Coli Bacteremia Transmitted by Fecal Microbiota Transplant." [In eng]. $N$ Engl J Med 381, no. 21 (Nov 21 2019): 2043-50.

Dethlefsen, Les, Sue Huse, Mitchell L Sogin, and David A Relman. "The Pervasive Effects of an Antibiotic on the Human Gut Microbiota, as Revealed by Deep 16s Rrna Sequencing." PLoS biology 6, no. 11 (2008).

Dethlefsen, Les, and David A Relman. "Incomplete Recovery and Individualized Responses of the Human Distal Gut Microbiota to Repeated Antibiotic Perturbation." Proceedings of the National Academy of Sciences 108, no. Supplement 1 (2011): 455461.

Eiseman, B., W. Silen, G. S. Bascom, and A. J. Kauvar. "Fecal Enema as an Adjunct in the Treatment of Pseudomembranous Enterocolitis." [In eng]. Surgery 44, no. 5 (Nov 1958): 854-9.

Food, US, and Drug Administration. "Guidance for Industry: Enforcement Policy Regarding Investigational New Drug Requirements for Use of Fecal Microbiota for Transplantation to Treat Clostridium Difficile Infection Not Responsive to Standard Therapies. 2016." 2019.

Goldenberg, Simon D, Rahul Batra, Ian Beales, Jonathan Leith Digby-Bell, Peter Miles Irving, Lee Kellingray, Arjan Narbad, and

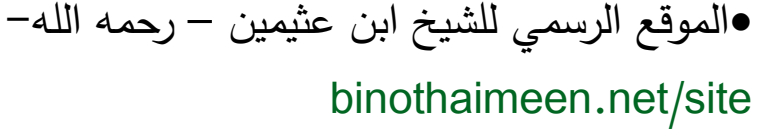

Ngozi Franslem-Elumogo. "Comparison of Different Strategies for Providing Fecal Microbiota Transplantation to Treat Patients with Recurrent Clostridium Difficile Infection in Two English Hospitals: A Review." Infectious diseases and therapy 7, no. 1 (2018): 71-86.

Kelly, CP, and JT Lamont. "AntibioticAssociated Diarrhea, Pseudomembranous Enterocolitis, and Clostridium DifficileAssociated Diarrhea and Colitis." Sleisenger and Fordtran's Gastrointestinal and Liver Disease, 9th edn. Saunders: Pennsylvania (2010): 1889-903.

McDonald, L Clifford, Dale N Gerding, Stuart Johnson, Johan S Bakken, Karen C Carroll, Susan E Coffin, Erik R Dubberke, et al. "Clinical Practice Guidelines for Clostridium Difficile Infection in Adults and Children: 2017 Update by the Infectious Diseases Society of America (Idsa) and Society for Healthcare Epidemiology of America (Shea)." Clinical Infectious Diseases 66, no. 7 (2018): e1-e48.

Ramai, Daryl, Karl Zakhia, Paul J Fields, Vahe Shahnazarian, Andrew Ofosu, Jonathan K Lai, Shannon Chang, and Madhavi Reddy. "Mo1970-Efficacy of Colonoscopy, Nasogastric Tube, Enema, and Capsule Fecal Microbiota Transplantation in the Treatment of 1,191 Patients with Recurrent Clostridium Difficile Infection: A Systematic Review and Meta-Analysis." Gastroenterology 156, no. 6 (2019): S-906-S-07.

Reigadas, Elena, María Olmedo, Maricela Valerio, Silvia Vázquez-Cuesta, Luis Alcalá, Mercedes Marín, Patricia Muñoz, and Emilio Bouza. "Fecal Microbiota Transplantation for Recurrent Clostridium Difficile Infection: Experience, Protocol, and Results." Revista Española de Quimioterapia 31, no. 5 (2018): 411. 
Rohlke, Faith, Christina M Surawicz, and Neil Stollman. "Fecal Flora Reconstitution for Recurrent Clostridium Difficile Infection: Results and Methodology." Journal of clinical gastroenterology 44, no. 8 (2010): 567-70.

Steele, Jennifer, Nicola Parry, and Saul Tzipori. "The Roles of Toxin a and Toxin B in Clostridium Difficile Infection: Insights from the Gnotobiotic Piglet Model." Gut microbes 5, no. 1 (2014): 53-57.

Tauxe, W. M., T. Dhere, A. Ward, L. D. Racsa, J. B. Varkey, and C. S. Kraft. "Fecal Microbiota Transplant Protocol for Clostridium Difficile Infection." Lab Med 46, no. 1 (Winter 2015): e19-23.

Van Nood, E, P Speelman, EJ Kuijper, and JJ Keller. "Struggling with Recurrent Clostridium Difficile Infections: Is Donor Faeces the Solution?". Eurosurveillance 14, no. 34 (2009): 19316.
Yoon, Sonia S, and Lawrence J Brandt. "Treatment of Refractory/Recurrent C. Difficile-Associated Disease by Donated Stool Transplanted Via Colonoscopy: A Case Series of 12 Patients." Journal of clinical gastroenterology 44, no. 8 (2010): 562-66.

Youngster, Ilan, Jasmin Mahabamunuge, Hannah K Systrom, Jenny Sauk, Hamed Khalili, Joanne Levin, Jess L Kaplan, and Elizabeth L Hohmann. "Oral, Frozen Fecal Microbiota Transplant (Fmt) Capsules for Recurrent Clostridium Difficile Infection." BMC medicine 14, no. 1 (2016): 134. 


\title{
Title: Medical and Islamic Jurisprudence study of Using Fecal Microbiota Transplant to treat the Multi-antibiotic Resistant Bacteria "Clostridium difficile" infection.
}

\author{
Dr. Amal Mohammed Faleh Alsogir \\ Associate professor in Islamic Jurisprudence, Shari'ah College, \\ Imam Mohammah Ibn Saud Islamic University \\ Dr. Najla Abdullah Sulaiman Obaid \\ Assistant professor of Pharmaceutical Sciences, College of Pharmacy, \\ Umm Al-Qura University
}

\begin{abstract}
FMT) treatment for Clostridium difficile infection in Islamic jurisprudence point of view. This infection is a serious condition, despite the fact of low infection rate in the Middle East countries, it has high mortality rate for hospitalized patients with pseudomembranous colitis. The recurrence and resistance to multiple antibiotics cases can be treated with invasive method which inserting microbiota using fecal transplant material.

This study is divided into three main parts: introduction, sub-sections and a conclusion. The introduction is divided into two sub-headings; 1 . Clostridium difficile overview and 2. diagnostic and treatment protocols. The sub-section is the Islamic juristic study for the treatment with FMT which is divided into two subheadings.

To conclude, this infection is usually treated with antibiotics for long period but the sever and recurrent infection can be treated effectively with FMT. The FMT is invasive method which includes many forms each has its own specific Fatwa*. All treatment protocols are considered permitted in Islam, however, the treatment with human and animal remains is not permitted. FMT treatment by rectal and colonoscopy route of administration are permitted based on the condition and burden of the critical and unresponsiveness to antibiotics treatment situation. It is better to not start FMT before using antibiotics approach and be certain that antibiotics are not effective in the sever condition. We recommend that FMT protocol must be studied clinically and by Islamic jurisprudence in a wider range to weigh between the risks and benefits for FMT approach.
\end{abstract}

Keywords: Bacterial infection treatment, Clostridium difficile infection, fecal microbiota transplant, medical and Islamic jurisprudence studies. 